\title{
Chapter 4 \\ Sustainable Product-Service System \\ Applied to Distributed Renewable \\ Energies
}

\subsection{Sustainable Product-Service System Applied to Distributed Renewable Energy: A Win-Win Opportunity}

We argued in previous chapters that Distributed Renewable Energy (DRE) generation is a promising approach towards sustainable energy for All. Aside, we described the Sustainable Product-Service System (S.PSS) model, as promising one towards sustainable development, even in low- and middle-income contexts. In this chapter, we describe the application of the Sustainable Product-Service System (S.PSS) to Distributed Renewable Energy (DRE) as a win-win opportunity for the diffusion of sustainable energy, even in low- and middle-income contexts.

It is clear that we need to undergo a paradigm shift in the way we produce, supply and use the energy.

Indeed, to reach the shift, will by coupling the two models, mean to: shift from centralised and non-renewable energy system to distributed renewable energy systems, in which the user can be the prosumer (consumer + producer) of her/his energy with small generator units nearby or at the point of use sourced by sun, wind and all other forms of renewable energy. Furthermore, in case of energy systems, the shift from individual ownership consumption to Sustainable Product-Service System would entail that:

- would be a model where the providers retain the ownership or at least some responsibilities over the life cycle of the small generator unit (of renewable energy) and eventually of the products that use the electricity, i.e. the Energy-Using Products/Equipment (EUP, EUE);

- customers pay per use/period, thus reducing/avoiding the (initial) investment cost of the small energy generator unit and eventually of the Energy-Using Products/Equipment; 
- the shift from the individual ownership to the satisfaction of an (energy) need, leading to avoid (unexpected) life cycle costs for the customer, as maintenance or repair on the small energy generator unit and eventually of the Energy-Using Products/Equipment, thus reducing the risk of drop-off.

In the next paragraph, a scenario of this paradigm shift is presented (Fig. 4.1).

\subsection{Scenario for S.PSS Applied to Distributed Renewable Energy}

This chapter describes the scenario ${ }^{1}$ - a new picture and the new narration of sustainable production and consumption systems - characterised by the application of the promising model of Sustainable Product-Service Systems (S.PSS) to Distributed Renewable Energy (DRE) in low- and middle-income contexts, and aimed to inspire the design of sustainable energy solutions, accessible by All.

This scenario is described by four visions, each representing a possible win-win configuration of S.PSS applied to DRE in low- and middle-income contexts, i.e. combining sociocultural, organisational and technological factors, fostering solutions with a low environmental impact, a high socioethical quality and a high economic and competitive value.

The four visions narrate the scenario and are outlined within two polarity axes. The horizontal axis, i.e. different customers of the sustainable energy solutions, the final user (B2C - either individual or local community), or entrepreneur/business (B2B). The vertical axis highlights whether the energy solution offers Distributed Renewable Energy generator (e.g. solar panel system plus its components such as storage, inverter, wires), or both the Distributed Renewable Energy generator and one or more Energy-Using Products or Energy-Using Equipments (e.g. phone and television are Energy-Using Products; woodworking machine and sewing machine are Energy-Using Equipment).

The following narration of the four visions, which emerged as an intersection of the two axes, defines the picture of the overall scenario:

- Energy for all in daily life (Vision 1);

- Energise your business without initial investment cost (Vision 2);

- 'Pay x use' for your daily life products and energy (Vision 3) and

- Start-up your business paying per period for equipment and energy (Vision 4) (Fig. 4.2).

Below a short description introduces each vision of the scenario (Fig. 4.3).

\footnotetext{
${ }^{1}$ A Sustainability Design Orienting Scenario (SDOS) has been developed as the application of the Sustainable Product-Service System (S.PSS) model to Distributed Renewable Energy (DRE). The scenario was developed with the following steps: case studies research, guidelines definition, workshop sessions and visions development.
} 


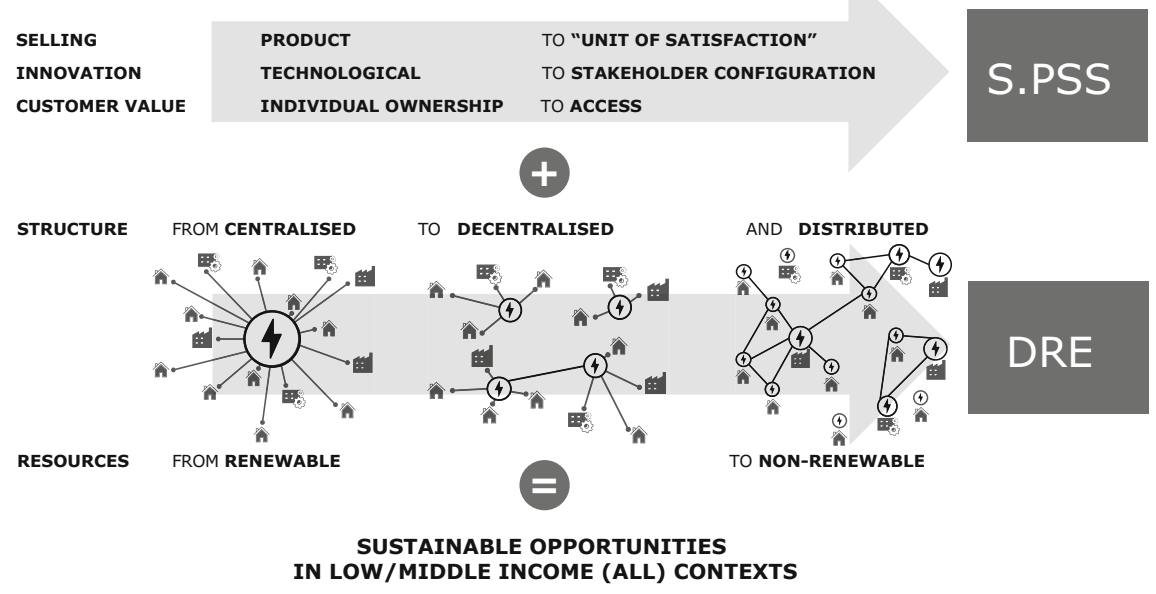

Fig. 4.1 The coupling of the 2 paradigm shifts represented by S.PSS and DRE. Source designed by the Authors

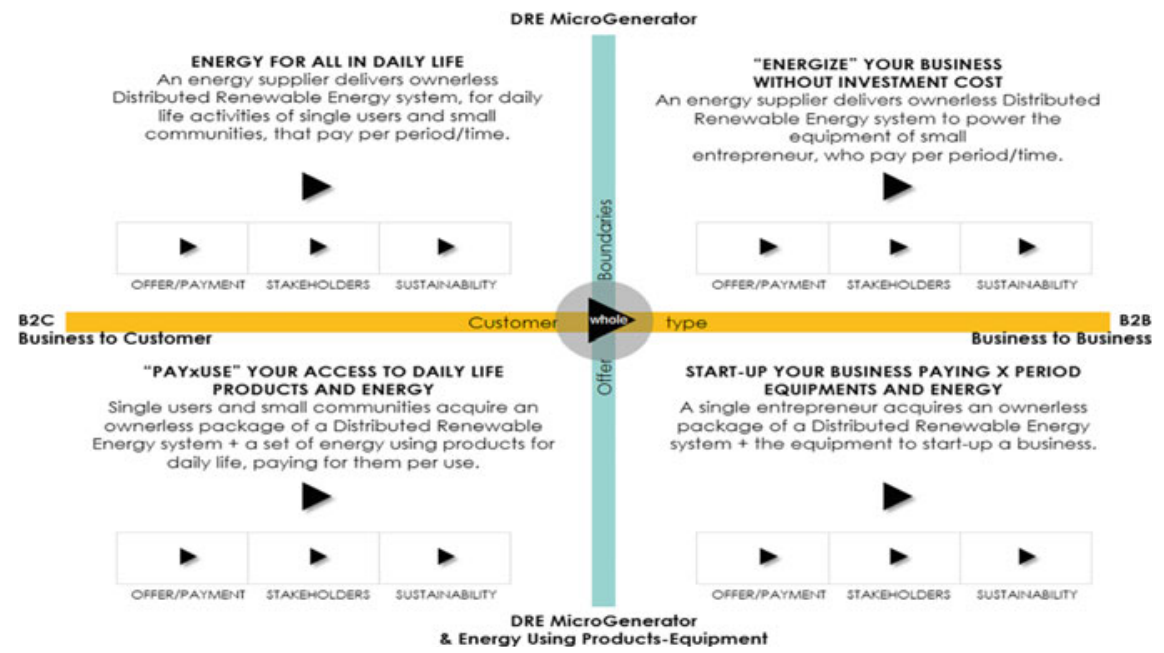

Fig. 4.2 The sustainable energy for all scenario. Source designed by the Authors

\subsubsection{Energy for All in Daily Life (Vision 1)}

The energy for all in daily life presents the offer of a Distributed Renewable Energy (DRE) micro-generator to a final customer (B2C). Indeed, it could be that: 'an energy supplier delivers an ownerless Distributed Renewable Energy system, for daily life activities, to single users and small communities who pay per period/ 


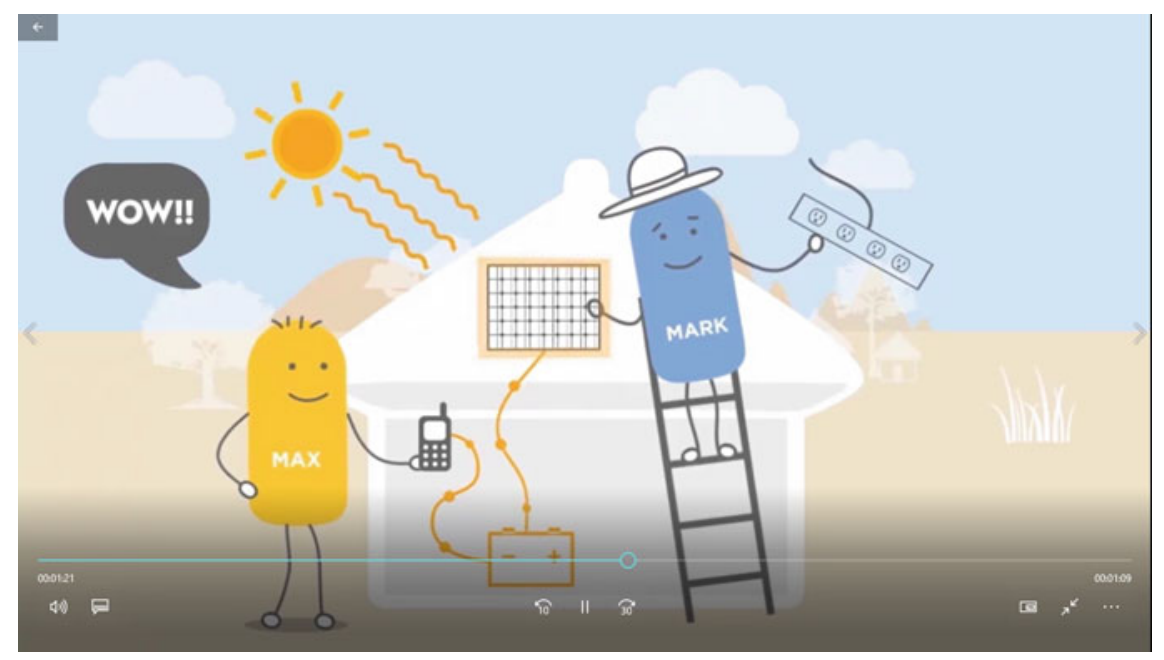

Fig. 4.3 Screenshots from the video 'Energy for all in daily life'. Source Vanitkoopalangkul [58]

time'. This implies that the ownership of the Distributed Renewable Energy system (e.g. solar panel, wires, storage) stays with the energy supplier, who covers both the initial investment cost (e.g. the purchase of micro-generator and its components and their installation) and life cycle costs (e.g. maintenance and repair). The customer makes customisable periodic payments to access his/her (energy) satisfaction. This configuration makes access to energy economically affordable even in low- and middle-income contexts, so that the quality of life could be greatly improved, especially in relation to health and security.

The following short story illustrates one possible situation in a low-income context: 'Max, inhabitant of a rural village, has no access to energy. Therefore, he uses an oil lamp for light and he goes to the closest village to charge his phone. If he can have a solar system installed on his roof, guaranteeing secure energy access, he can avoid daily problems, and improve his and his family's quality of life.'

The story could change coherently with the energy for all in daily life vision presented above (many other could be imagined): 'Max doesn't have to buy the Distributed Renewable Energy micro-generator and its components; he just uses them by paying per period a fixed amount of money. Ownership and related services remain with the energy supplier, who is interested in reducing maintenance and repair needs, improving his own profit while reducing the environmental impact of the system' (Fig. 4.4).

A video of this story is available at: https://www.youtube.com/watch?v= 93NXZLpxnUQ. 


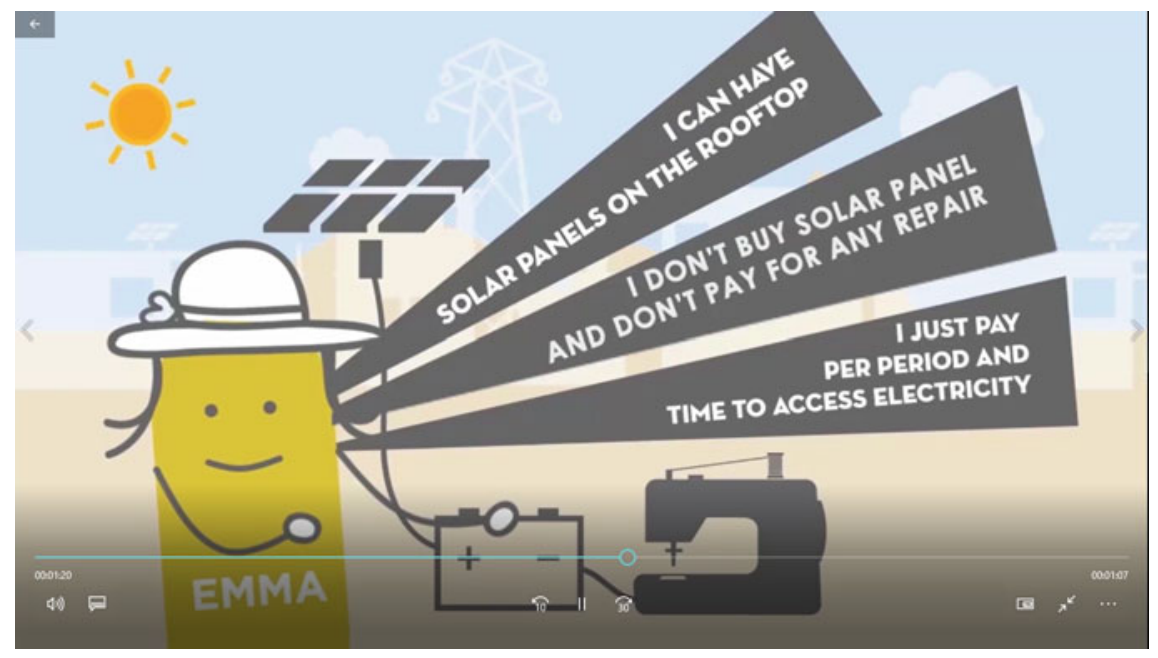

Fig. 4.4 Screenshots from the video energise your business without investment cost. Source Vanitkoopalangkul [58]

\subsubsection{Energise Your Business Without Initial Investment Cost (Vision 2)}

The energise your business without initial investment cost introduces a business-to-business (B2B) opportunity, in which 'an energy supplier delivers an ownerless Distributed Renewable Energy system to power the equipment of a small entrepreneur, who pays per period/time'. Even in this case, the Distributed Renewable Energy system is not owned by the customer. This reduces the risks for the customers, such as small entrepreneurs or businesses, who do not have to face any initial investment, except for the purchase of the necessary Energy-Using Equipment (e.g. sewing machine for a tailor shop) which are not included in the offer. In this way, small entrepreneurs/businesses even in low- and middle-income contexts can receive stable energy access, thus being able to guarantee the production/delivery of a predetermined quantity of products/services within a given time, thus satisfying clients and opening market opportunities.

The following short story illustrates one possible situation in a low-income context: 'Kate and Tom, tailors in a rural village, have no stable access to Energy consequently they still use a diesel generator to power their sewing machine. If they can have a solar system installed in their tailor shop, guaranteeing secure energy access, they can guarantee on time delivery and avoid losing clients.'

The story could change coherently with energise your business without initial investment cost vision presented above (many other could be imagined): 'Kate and Tom don't have to buy the Distributed Renewable Energy micro-generator and components, but only have to pay a fixed rate per period. Ownership and related 


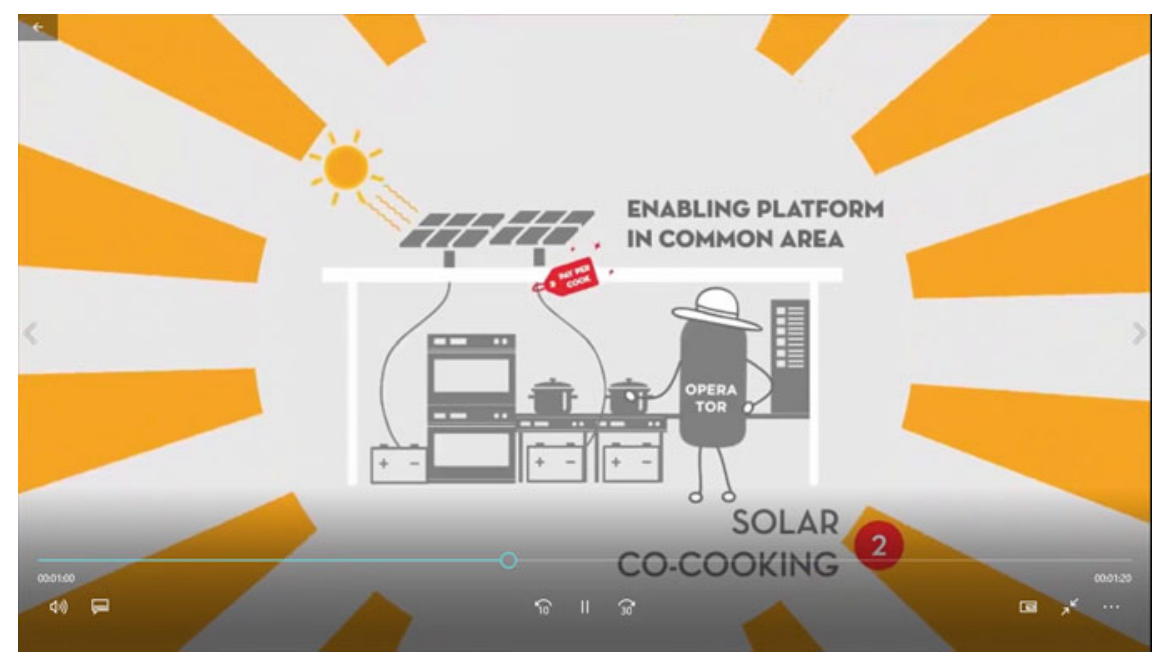

Fig. 4.5 Screenshots from the video 'Pay x use' for your daily life products and energy. Source Vanitkoopalangkul [58]

services stay with the energy supplier, who is interested in reducing maintenance and repair needs, improving his own business while reducing the environmental impact' (Fig. 4.5).

A video of this story is available at: https://www.youtube.com/watch?v= DB3XSYJ3wvg.

\subsection{3 'Pay $x$ Use' Your Daily Life Products and Energy (Vision 3)}

The 'Pay $x$ use' your daily life products and energy presents a business-to-customer (B2C) offer of a Distributed Renewable Energy (DRE) micro-generator (and the related components) plus related Energy-Using Products, where 'single users and small communities acquire an ownerless package consisting of a Distributed Renewable Energy system plus a set of energy using products for daily life, paying for them per use.' Similar to the two previous visions, even in this case, the Distributed Renewable Energy micro-generator and the related components are owned by the energy supplier. Different from previous visions, the Energy-Using Products (e.g. burner, oven) are included in the ownerless offer to the customer. This configuration cuts the initial investment costs (e.g. purchase, installation) of both Distributed Renewable Energy micro-generator and Energy-Using Products, as well as their life cycle costs (e.g. maintenance and repair) for the customers. The customers pay for the (energy) services they use, thus increasing affordability of the solution. For many people who still using firewood for cooking, access to clean 
energy could greatly improve their quality of life, reducing diseases caused by toxic emissions from the fire.

The following short story shows one possible situation in a low-income context: 'Mary and Ryan, are a family living in a rural village where cooking with firewood is still the main solution, due to the lack of access to sustainable energy. If they can have a solar system installed on their roof, guaranteeing secure energy access, they can reduce health risks, while gaining time no longer needed to collect firewood.'

The story could change coherently with 'Pay $x$ use' your daily life products and energy vision presented above (many other could be imagined): 'Mary and Ryan can use the common kitchen based in the village to cook, where the energy used comes from the local Distributed Renewable Energy system. They don't have to buy any component or Energy Using Products in the kitchen, but they pay to cook. Ownership and related services stay with the energy supplier, who is interested in reducing maintenance and repair needs, improving their own business while reducing environmental impact.'

A video of this story is available at: https://www.youtube.com/watch? $\mathrm{v}=$ ri5IPoIO_6Q.

\subsubsection{Start-up Your Business Paying Per Period for Equipment and Energy (Vision 4)}

The 'Start-up your business paying per period for equipment and energy' presents an offer for small entrepreneurs/businesses (B2B) offer where 'a single entrepreneur acquires an ownerless package, consisting of a Distributed Renewable Energy system plus the equipment to start-up a business'. In this configuration, a small entrepreneur/business receives an ownerless Distributed Renewable Energy system package (e.g. carpenter's workshop) composed of a Distributed Renewable Energy micro-generator and related components and the related Energy-Using Equipment (e.g. circular saw, drill). The ownership of the full package is retained by the energy supplier or a partnership. This cuts the initial investment costs for the purchase of both the Distributed Renewable Energy micro-generator and the Energy-Using Equipment, as well as their life cycle costs for the small entrepreneur/business. This comes to be very relevant, especially in low- and middle-income contexts, where many small entrepreneurs/businesses cannot get a loan from traditional banks. With stable access to energy, they could increase their business opportunities and working conditions, while empowering local economic growth.

The following story shows one possible situation in low-income context: 'Ben, carpenter in a big city, wants to move back to his own village to open a carpentry workshop, but no energy access is available. If he can have a solar system installed in his carpentry workshop in the village, guaranteeing secure energy access, he can start his business, offering on time delivery, with the most updated and energy efficient energy using equipment.'

The story could change coherently with start-up your business paying per period for equipment and energy vision above (many other could be imagined): 'Ben 


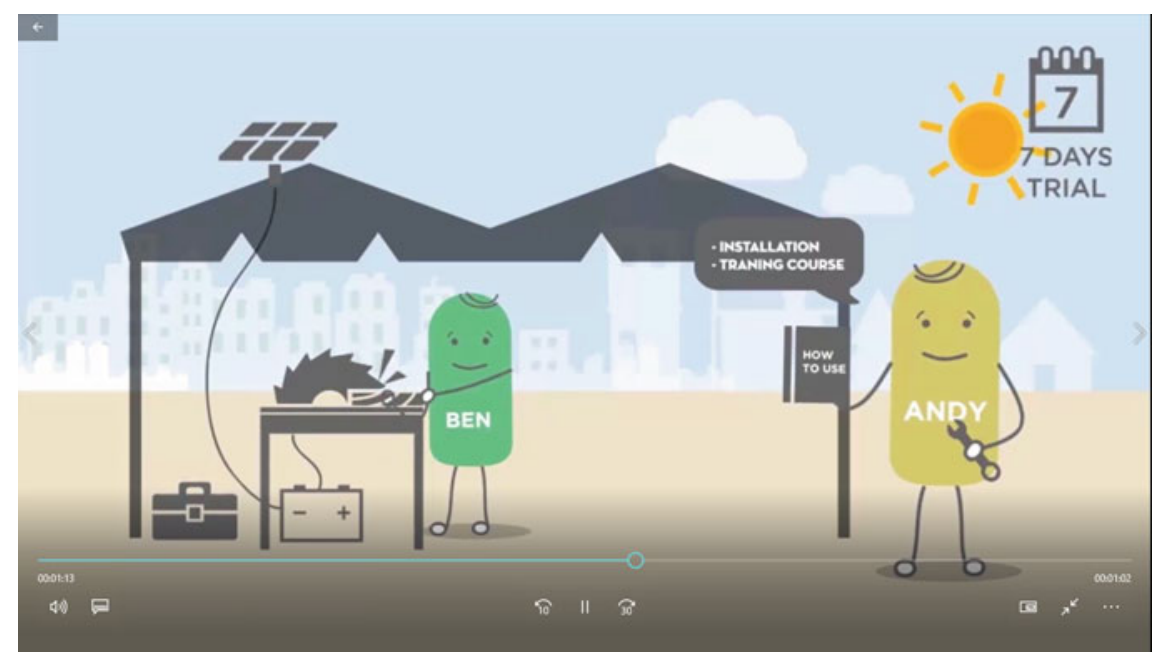

Fig. 4.6 Screenshots from the video 'Start-up your Business' paying per period for equipment and energy. Source Vanitkoopalangkul [58]

doesn't have to buy the Distributed Renewable Energy micro-generator and components or the Energy Using Equipment for his shop. He just pays a fixed rate per period. Ownership and related services stay with the energy supplier who is interested in reducing maintenance and repair needs, improving their own business while reducing environmental impact' (Fig. 4.6).

A short video of this possible offer is available at: https://www.youtube.com/ watch? $=14$ sdFSI 8 A 5 M.

\subsection{S.PSS Applied to DRE: Sustainability Potential Benefits}

The potential benefits of S.PSS and DRE have been extensively discussed for each model respectively on Sects. 3.3 and 2.1. This section discusses the potential sustainability benefits derived from applying S.PSS to DRE. It has, in fact, been argued that the combination of these two models represents a promising approach to deliver sustainable energy solutions in low- and middle-income contexts [14, 57]. Several potential advantages can be identified [17].

\subsubsection{Environmental Benefits of S.PSS Applied to DRE}

The adoption of a S.PSS approach in DRE solutions would make energy providers/ manufacturers economically interested in seeking after environmentally beneficial solutions (as fully discussed in Sect. 3.3.1). In fact, if providers retain ownerships 
and responsibilities over the DRE generation unit/s and Energy-Using Products/ Equipment involved in the offer, the providers will be interested in extending lifespan of the physical elements of the solution, as well as interested in extending materials lifespan through recycling, energy recovery or composting. Furthermore, if providers are paid based on the performance delivered (and not per unit of product sold), they would be interested in reducing as much as possible the material and energy resources needed to provide that performance, as well as to design (offer) for passive/renewable resources optimisation. Additionally, in the case where S.PSS is applied to DRE solutions that promote a shared use of product/s (or some product's components, i.e. DRE generation unit, or Energy-Using Products/ Equipment) by multiple users, the more intensively these products are used, the higher the profit will be, i.e. proportional to the overall use time. So forth, having manufacturers/providers to keep ownership or at least some responsibilities over the DRE generator units and Energy-Using Products/Equipment, it represents a crucial aspect to encourage design for intensive use of product/s. Finally, if the S.PSS applied to DRE solution includes an all-inclusive service package to manage the toxic or harmful product/s in use and/or end-of-life, the producer/provider is driven by economic interests to design (offer) for toxicity/harmfulness minimisation.

\subsubsection{Socioethical Benefits of S.PSS Applied to DRE}

From a user's perspective, a S.PSS approach applied to DRE can increase customer (energy) satisfaction. This could happen because S.PSS offers access to (energy) satisfaction rather than mere (energy) product ownership, thus reducing/avoiding initial investment costs and running costs, e.g. maintenance and repair of energy products, which are frequently too high for low- and middle-income customers. In addition, a S.PSS applied to DRE offer can be tailored to the customers' particular (cultural and ethical) needs more easily than traditional product-based offers while making goods and (energy) services more easily accessible to All and increasing reliability.

From a business perspective, since S.PSSs are characterised by being labour and relationship-intensive solutions, and since both DRE and S.PSS require labour activities to be carried out at a local level, this can lead S.PSS applied to DRE solutions to a greater involvement of more local, rather than global, socio-economic stakeholders. This could result in an increase in local employment (as explained before) and local dissemination of skills and competences $[53,56]$, i.e. facilitating new business start-up in low- and middle-income contexts. Additionally, the selling of all-inclusive life cycle services with the equipment might reduce/avoid running cost for equipment maintenance, repair, upgrade, etc., frequently too high for lowand middle-income entrepreneurs, thus avoiding interruption of equipment use. Finally, S.PSS applied to DRE solutions offers (energy) services/business opportunities without initial investment costs, thus opening new market opportunities for local entrepreneurs via new potential low- and middle-income customers. 


\subsubsection{Economic Benefits of S.PSS Applied to DRE}

From a user's perspective, S.PSS applied to DRE solutions does not require upfront payment for the products included (DRE generation units and potentially Energy-Using Products/Equipment). As result, low-income consumers can easily get access to modern electricity services without the need of making high initial investments [54].

From a business perspective, adopting a S.PSS approach can improve the strategic positioning and competitiveness of manufacturers/providers [21, 41, 62], establish a longer and stronger relationship with customers [11, 40] and build up barriers to entry for potential new competitors [21]. Finally, S.PSS applied to DRE solutions offers opportunities to strengthen the local economy and increase local employment. In fact, compared to traditional offers, S.PSS is more focused on the context of use, meaning that the service elements must be created at the same time and often at the same place when and where they are consumed [55]. Thus, skilled personnel might be empowered at a local level to carry out services such as installation, maintenance, repair, training, etc. The same is true for DRE systems which, compared to centralised systems, are characterised by a multiplicity of energy production units dispersed in the territory.

Combining a S.PSS approach offers additional advantages. From a user's perspective, a S.PSS approach can increase customer satisfaction because a S.PSS offer can be tailored to their particular (cultural and ethical) needs more easily than traditional product-based offers [53].

From a community angle, since S.PSSs are characterised by being labour and relationship-intensive solutions, and since both DRE and S.PSS require labour activities to be carried out at a local level, this can lead to a greater involvement of more local, rather than global, socio-economic stakeholders. Therefore, this could result in an increase in local employment (as explained before) and local dissemination of skills and competences $[53,56]$.

Of course, these potential benefits must be verified case-by-case, and balanced against the potential limitations and rebound effects (such as, for example, careless behaviours of users on not owned products). For this reason, S.PSS applied to DRE must be specifically designed, developed and delivered, in order to generate the above-mentioned sustainability advantages.

\subsection{S.PSS Applied to DRE: A New Classification System and 15 Archetypal Models}

S.PSS and DRE have been widely studied over the past decades, and knowledge has been built on how to classify these models. However, S.PSS and DRE have been only studied separately, and thus a comprehensive classification that looks at 
the combination of these two models is missing. This section puts forward a new classification system for S.PSS applied to DRE and describes 15 archetypal models of S.PSS applied to DRE [17].

\subsubsection{Classification System}

In the development of the new classification system, the starting point was the identification of the characterising dimensions used to classify S.PSS and DRE (Table 1.1).

Regarding DRE, several approaches have been proposed in the past to classify DRE models. These classification systems are built considering different combinations of characterising dimensions: energy system, including type of energy generation and type of energy source (e.g. [36]), value proposition and payment structure (e.g. [19]), capital financing (e.g. [4]), energy system ownership (e.g. [48]), energy system operation [50], organisational form (e.g. [64]) and target customer (e.g. [64]). It is important to highlight that no classification system encompasses all these characterising dimensions. They focus on a few (or sometimes only a single) dimensions, and thus they are individually unable to cover the complexity characterising DRE models.

Regarding S.PSS, the majority of the S.PSS classifications proposed in the past agree on three main S.PSS categories: product-oriented, use-oriented and resultoriented S.PSSs [52]. Gaiardelli et al. [20] carried out an extensive analysis on the dimensions taken into consideration in these classifications and identified five main characterising dimensions: value proposition, product ownership, product operation, provider/customer relationship and environmental sustainability potential.

As shown in Table 4.1, some of the identified characterising dimensions overlap, while some other are specifically used for DRE or S.PSS. For this reason, there is a need for a new classification system capable of simultaneously taking into consideration all the major dimensions characterising S.PSS applied to DRE (see Table 4.2).

Table 4.1 List of S.PSS and DRE dimensions

\begin{tabular}{l|l}
\hline DRE dimensions & S.PSS dimensions \\
\hline 1. Energy system & - \\
\hline 2. Value proposition/payment structure & 2. Value proposition/payment structure \\
\hline 3. Capital financing & - \\
\hline 4. Energy system ownership & 4. Product ownership \\
\hline 5. Organisational form & - \\
\hline 6. Energy system operation & 6. Product operation \\
\hline 7. Target customer & - \\
\hline- & 8. Provider/customer relationship \\
\hline- & 9. Environmental sustainability potential \\
\hline
\end{tabular}

Source Emili et al. [17] 
Table 4.2 Dimensions characterising S.PSS applied to DRE

\begin{tabular}{|c|c|c|}
\hline $\begin{array}{l}\text { S.PSS\&DRE } \\
\text { Dimension }\end{array}$ & Description & Details \\
\hline 1. Energy system & $\begin{array}{l}\text { Defines the connection type (stand-alone, } \\
\text { grid-based systems) and renewable source } \\
\text { involved (solar, wind, biomass etc.) }\end{array}$ & $\begin{array}{l}\text { Stand-alone system: mini-kit, } \\
\text { individual energy system, } \\
\text { charging station } \\
\text { Grid-based system: isolated } \\
\text { mini-grid, connected mini-grid } \\
\text { Energy sources: solar, hydro, } \\
\text { biomass, wind, human power }\end{array}$ \\
\hline $\begin{array}{l}\text { 2. Value } \\
\text { proposition/ } \\
\text { payment structure }\end{array}$ & $\begin{array}{l}\text { Represents the value offered to the } \\
\text { customer, i.e. the combination of product } \\
\text { and services for which the customer is } \\
\text { willing to pay and the payment structure }\end{array}$ & $\begin{array}{l}\text { Product-oriented S.PSS: } \\
\text { - Pay-to-purchase with advice, } \\
\text { training and consultancy } \\
\text { services } \\
\text { - Pay-to-purchase with additional } \\
\text { services } \\
\text { Use-oriented S.PSS: } \\
\text { - Pay-to-lease } \\
\text { - Pay-to-share/rent/pool } \\
\text { Result-oriented S.PSS: } \\
\text { - Pay-per-energy consumed } \\
\text { - Pay-per-unit of satisfaction }\end{array}$ \\
\hline $\begin{array}{l}\text { 3. Capital } \\
\text { financing }\end{array}$ & $\begin{array}{l}\text { Indicates how capital is provided for the } \\
\text { energy solution and determines cost } \\
\text { recovering and tariff structure }\end{array}$ & $\begin{array}{l}\text { Fully subsidised, } \\
\text { quasi-commercial, commercially } \\
\text { led }\end{array}$ \\
\hline $\begin{array}{l}\text { 4. Ownership } \\
\text { (of the energy } \\
\text { system and } \\
\text { Energy-Using } \\
\text { Products) }\end{array}$ & $\begin{array}{l}\text { Refers to who owns the energy system and } \\
\text { products involved in the offer, i.e. the } \\
\text { provider, the end user or a number of users }\end{array}$ & Customer or provider \\
\hline $\begin{array}{l}\text { 5. Organisational } \\
\text { form }\end{array}$ & $\begin{array}{l}\text { Indicates the nature of the organisation } \\
\text { providing the energy solution }\end{array}$ & $\begin{array}{l}\text { Public sector-based, utility, NGO, } \\
\text { community, PPP/hybrid, private } \\
\text { sector-based }\end{array}$ \\
\hline $\begin{array}{l}\text { 6. Energy system } \\
\text { operation }\end{array}$ & Defines who operates the energy system & Customer or provider \\
\hline 7. Target customer & $\begin{array}{l}\text { Indicates the type of end user (e.g. } \\
\text { household, community, public building) }\end{array}$ & $\begin{array}{l}\text { Individual customer or } \\
\text { community }\end{array}$ \\
\hline $\begin{array}{l}\text { 8. Provider/ } \\
\text { customer } \\
\text { relationship }\end{array}$ & $\begin{array}{l}\text { Refers to the nature and intensity of } \\
\text { interaction between the two actors and } \\
\text { varies from transaction-based } \\
\text { (product-oriented S.PSSs) to } \\
\text { relationship-based (result-oriented S.PSSs) } \\
\text { according to the responsibilities and } \\
\text { activities performed on the product [20], } \\
\text { [44] }\end{array}$ & $\begin{array}{l}\text { Transaction-based or } \\
\text { relationship-based }\end{array}$ \\
\hline $\begin{array}{l}\text { 9. Environmental } \\
\text { sustainability } \\
\text { potential }\end{array}$ & $\begin{array}{l}\text { Refers to the S.PSS environmental impact, } \\
\text { which can potentially be lower than } \\
\text { traditional product-based business models. } \\
\text { It generally goes from high sustainability } \\
\text { potential in result-oriented S.PSSs, to low } \\
\text { sustainability potential in product-oriented } \\
\text { S.PSSs [53] }\end{array}$ & $\begin{array}{l}\text { Low, medium or high } \\
\text { environmental sustainability } \\
\text { potential }\end{array}$ \\
\hline
\end{tabular}


The new classification system was developed as a polarity diagram, in the attempt of grouping the major S.PSS\&DRE characterising dimension into two groups (see Fig. 4.7).

The vertical axis includes:

- Value proposition (dimension \#2);

- Ownership (of energy system and Energy-Using Products) (dimension \#4);

- Energy system operation (dimension \#6);

- Provider/customer relationship (dimension \#8) and

- Environmental sustainability potential (dimension \#9).

These dimensions can in fact overlap one another:

- The value proposition (dimension \#2) ranges from product-oriented to use-oriented and result-oriented S.PSSs. This dimension is therefore strictly related to the ownership (of energy system and Energy-Using Products) (dimension \#4). In fact, in product-oriented S.PSSs, the final user is the owner of the product/s, while moving towards result-oriented services the ownership is retained by the provider;

- The value proposition can also be aligned with the energy system operation dimension (\#6), which refers to the management and operation of energy systems. In product-oriented and use-oriented S.PSSs, customers operate the energy

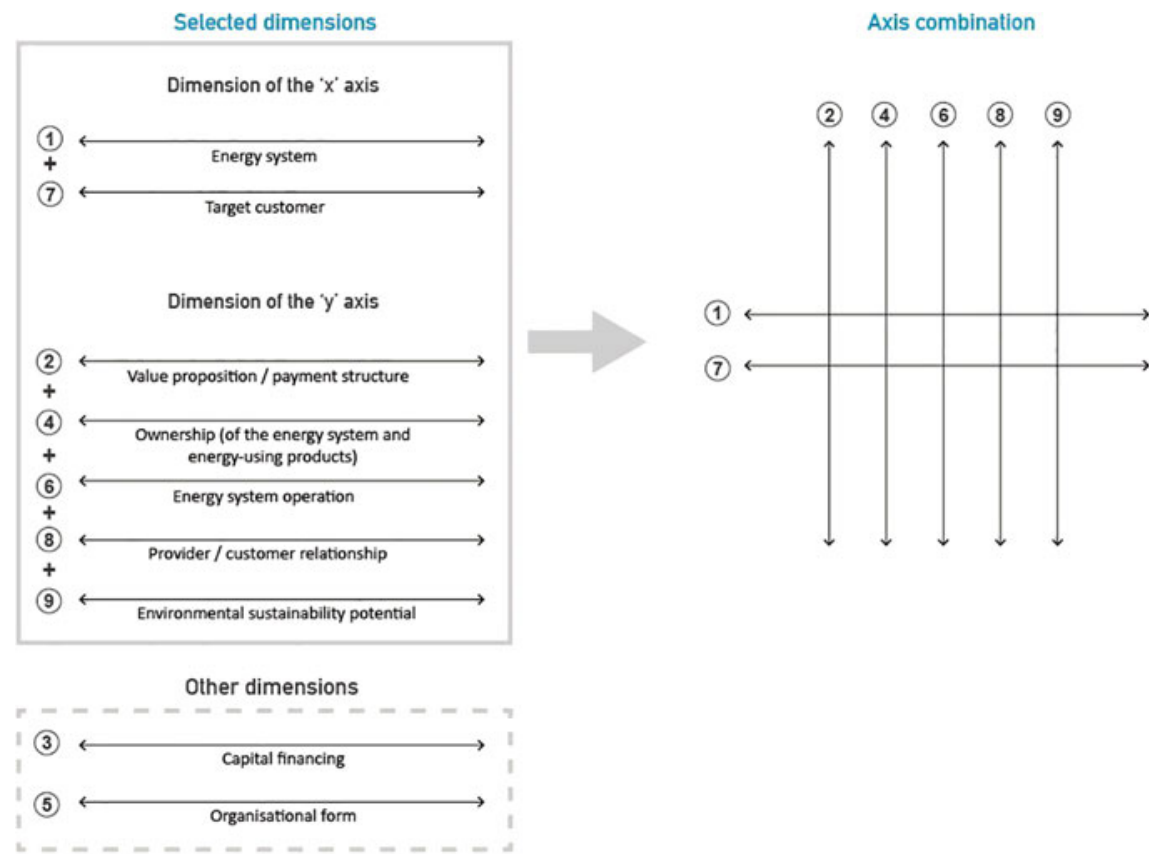

Fig. 4.7 Selection of dimensions' polarities and combination of axis used to build the classification system. Source Emili et al. [17] 
systems to achieve the results they aim to. In result-oriented S.PSSs, the provider is responsible for operating the system in order to deliver the agreed final result to the customer. When Energy-Using Products are included in the offer, their operation is always performed by end users (e.g. using lamps and other appliances), hence the polarity only refers to energy system operation;

- The provider/customer relationship dimension (\#8) ranges from being transactionbased in product-oriented S.PSSs, to relationship-based in result-oriented S.PSSs where a more intense relationship between provider and customers is created. For this reason, it can be aligned with the value proposition;

- Lastly, the environmental sustainability potential dimension (\#9) can be encompassed in this group and it ranges from high (for result-oriented S.PSSs and use-oriented) to low (for product-oriented S.PSSs).

The horizontal axis encompasses the following dimensions:

- Energy system (dimension \#1) and

- Target customer (dimension \#7).

The energy system dimension (\#1) focuses on the type of energy system, and includes stand-alone systems (mini-kit, individual energy system and charging station) and grid-based system (isolated mini-grid and connected mini-grid). For the purpose of this classification, the type of renewable source is not considered because this is transversal to the different types of energy systems. The energy system dimension is strictly related to the target customer dimension (\#7). In fact: stand-alone systems, such as mini-kits and home systems, are targeted to individual users; S.PSSs offered through charging stations (e.g. lanterns sharing systems) are targeted to groups of users; finally, S.PSSs linked to mini-grids are offered to communities.

The resulting polarity diagram, combining the horizontal and the vertical axis, is visualised in Fig. 4.8. The vertical axis distinguishes six main types of S.PSS:

In product-oriented S.PSSs:

- Pay-to-purchase with training, advice and consultancy services. In this model, energy systems (with or without Energy-Using Products) are sold to the customer together with some advice related to the product/s sold, such as how to efficiently use the system, how to dispose of it, management training, etc. This advice can be delivered in many ways (e.g. after the purchase, during the use of the product, through training courses);

- Pay-to-purchase with additional services. Here, the provider sells the energy system but also offers services related to the installation, use and or end-of-life phases. These services can include a financing scheme, a maintenance contract, an upgrading contract, an end-of-life take-back agreement, etc.

In use-oriented S.PSSs:

- Pay-to-lease. In leasing models, the provider keeps the ownership of the system (and is often responsible for maintenance, repair and disposal), while the customer pays a regular fee for an unlimited and individual access to the leased product; 


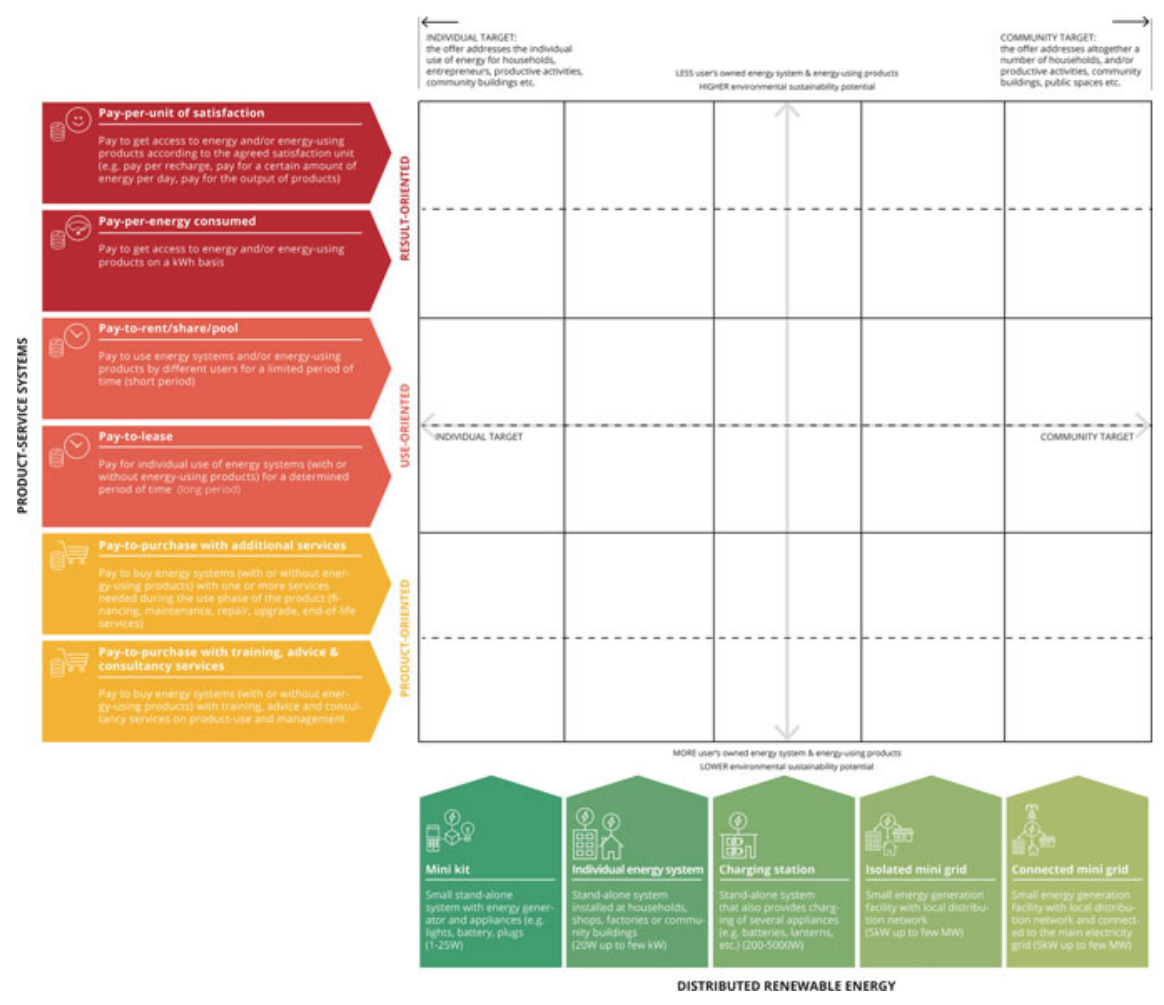

Fig. 4.8 Classification system. Source Emili [18]

- Pay-to-rent/share/pool. In this case, the provider keeps the ownership of the energy system and Energy-Using Products and is often responsible for maintenance, repair and disposal. Customers pay for the use of the Energy-Using Products (e.g. pay-per-hour) without having unlimited and individual access. Other clients in fact can use the product in other moments (different users can sequentially use the product).

In result-oriented S.PSSs:

- Pay-per-energy consumed. In this type of S.PSS, the provider offers a 'result' to customers and has the freedom of choosing the most appropriate technology to provide energy services. The energy solution provider keeps the ownership of the products (energy system and Energy-Using Products) and is responsible for maintenance, repair and disposal. Customers pay for the output of the system (energy) according to what they consume (pay-per-kWh);

- Pay-per-unit of satisfaction. Here, the provider offers access to energy (and/or Energy-Using Products) and customers pay according to the agreed satisfaction unit, e.g. pay-to-recharge products, pay for a certain amount of energy per day, pay for the output of products for a limited amount of time. The provider 
chooses the best technology to provide the 'satisfaction' and keeps ownership and responsibility for the products (energy system and Energy-Using Products) involved.

Different from existing classification systems, this new system encompasses the majority of the dimensions characterising S.PSS and DRE, and thus provides an overview of the possible different models of S.PSSs applied to DRE. In other terms, it is a unified classification system capable of mapping and illustrating the different characteristics of these models.

It is important to highlight that the developed polarity diagram excludes some of the characterising dimensions: in particular the capital financing (\#3) and the organisational form (\#5) dimensions. Despite being crucially important for the implementation of S.PSS applied to DRE, they are cross-cutting to different types of offer models. In fact, the same type of offer model of S.PSS applied to DRE can be provided by different types of organisational forms and through different capital financing solutions. In other terms, these dimensions are not crucial for the classification system and for characterising offer models of S.PSS applied to DRE.

\subsubsection{Archetypal Models of S.PSS Applied to DRE}

After building the classification system, this was populated with 56 case studies. The aim of this activity was to understand the current situation in terms of existing S.PSS+DRE models. Cases were selected in order to cover, as much as possible, all the possible differences in the characterising dimensions (e.g. different types of technologies and energy sources, different types of target customers). The only common characteristic is the context of application: selected cases are related to rural areas in low- or middle-income contexts.

The next step was to group them into clusters of similar cases. This led to the identification of 15 archetypal models of S.PSS applied to DRE [17]. Cases included within each archetypal model present similar key traits, such as type of value proposition and target customer, but their secondary characteristics (e.g. the organisational form, the capital financing) are sometimes different. Figure 4.9 provides an overview of the 15 archetypal models.

The following text describes each archetypal model, coupled with a stakeholder system map, a visualisation showing the actors involved in the S.PSS offer and their relationships. For each archetype, a case study is illustrated. In the next paragraph, archetypal models are described starting from the bottom of the diagram: first product-oriented and then use-oriented and result-oriented S.PSSs (See Figs. 4.10, 4.11, 4.12, 4.13, 4.14, 4.15, 4.16, 4.17, 4.18, 4.19, 4.20, 4.21, 4.22, 4.23 and 4.24).

In product-oriented S.PSSs, the first group of archetypal models (1,2 and 3) is related to pay-to-purchase with training, advice and consultancy services. 


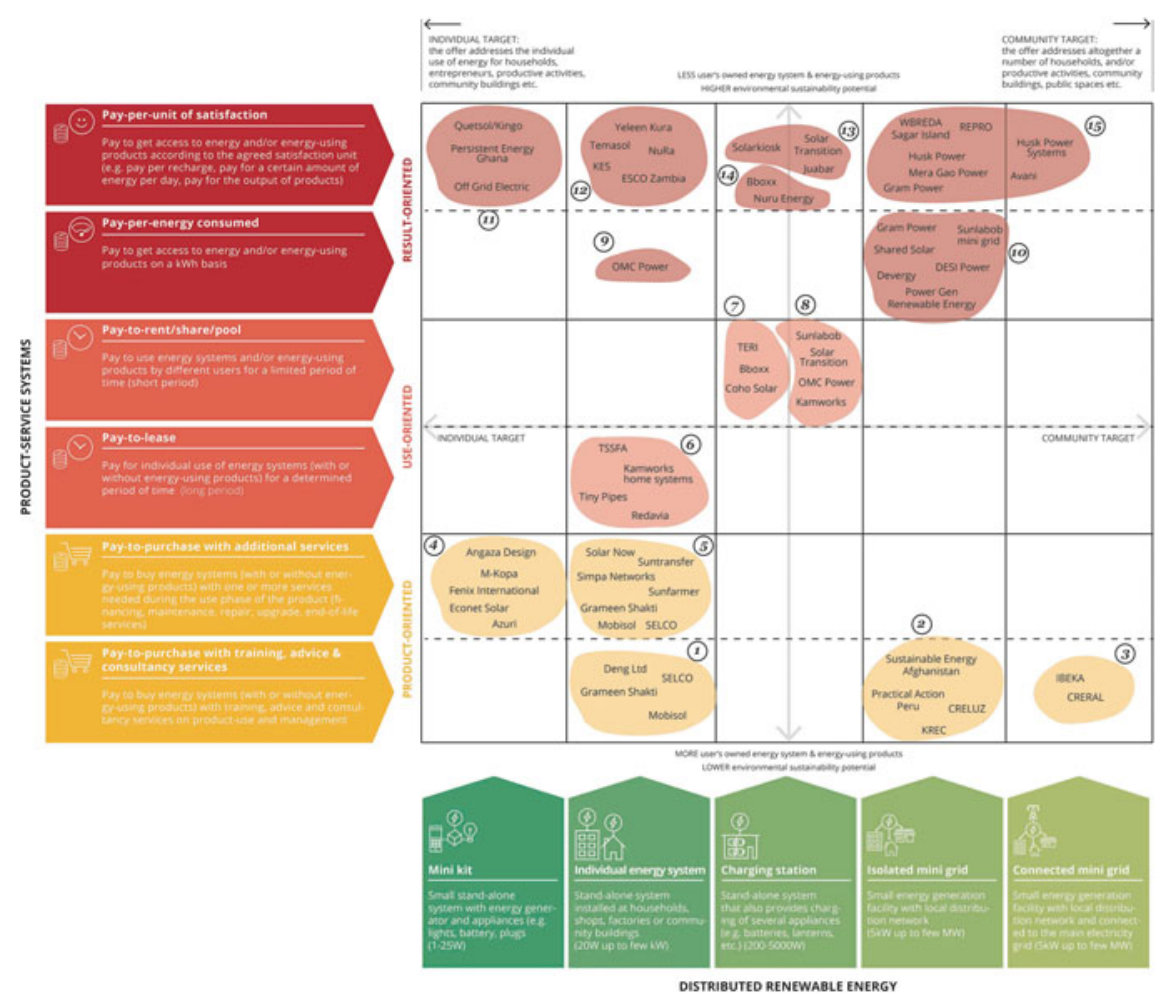

Fig. 4.9 Classification system with archetypal models. Source Emili [18]

1. Selling individual energy systems with advice and training services. In this model, the sale of individual energy systems (in most cases, solar home systems) is coupled with training and education. Depending on the target user, these services can focus on design, installation, repair and skills to develop a business on energy systems, or on basic maintenance and environmental awareness. Customers become owners of the systems at the moment of purchase and they are responsible for operation and maintenance.

\section{Case study:}

Mobisol/since 2010

Category: Solar Energy

Provider/s: Mobisol

Customers: Inhabitants

Location: East Africa

The company sells solar home systems with some additional services (financing, maintenance) and integrated mobile payment modality. Customers buy the chosen system and pay through mobile instalments over the credit period. The company 


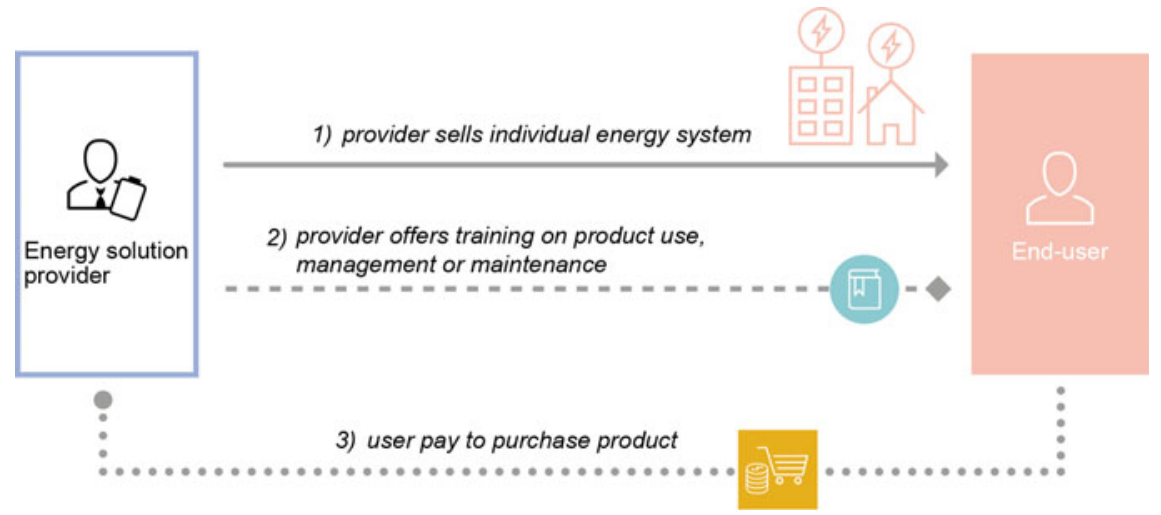

Fig. 4.10 Archetypal model 1: selling individual energy systems with advice and training services. Source Emili [18]

established the Mobisol Akademie, a training institution for staff, local entrepreneurs and contractors who wants to specialise in sales and technical support of solar home systems. The aim is to create local employment and capacity building and ensure that local expertise and assistance is provided.

2. Offering advice and training services for community-owned and-managed isolated mini-grids. The energy solution provider sells mini-grids to communities. Communities are responsible for operating and managing the system. They can also be in charge of designing a payment structure and fee collection. In addition to selling mini-grids, the provider offers a training service to a village committee on the operation, maintenance and management of the energy system. In some cases, communities may repay the installation with in-kind contributions such as labour.

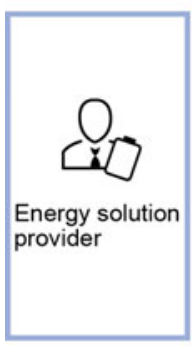

1) provider sells and installs mini grid
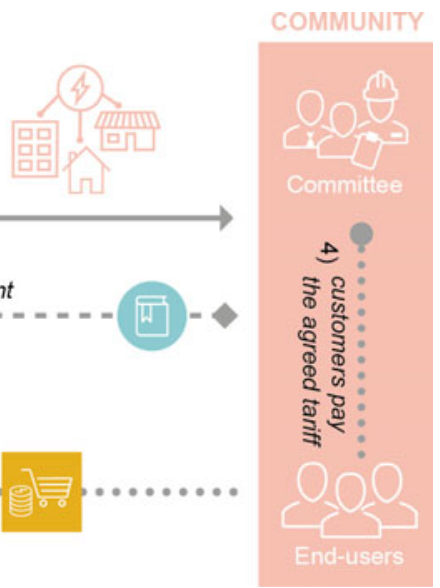

Fig. 4.11 Archetypal model 2: offering advice and training services for community-owned and community-managed isolated mini-grids. Source Emili [18] 


\section{Case Study:}

\section{Practical Action project}

Category: Hydropower Energy

Provider/s: Practical Action, local manufacturers, village committee, local technicians

\section{Customers: Local communities \\ Location: Perù}

The Practical Action NGO helps communities in the Andes region in installing and setting up mini-grids running on hydropower. Practical Action partners with local manufacturers to design the system, then involves the communities by setting up a village committee that will take care of fee collection and trains some technicians who will perform daily operation and maintenance. The community participates in the system installation with construction labour and becomes owner of the energy system. End users pay for the electricity they consume with tariffs that differ between the types of customers.

3. Offering advice and training services for community-owned and-managed connected mini-grids. This model is very similar to the previous one but, in this case, the mini-grid is connected to the main electricity grid. In this case, the system allows the community to not only produce and distribute energy to the local network but also to sell electricity to the national electricity supplier.

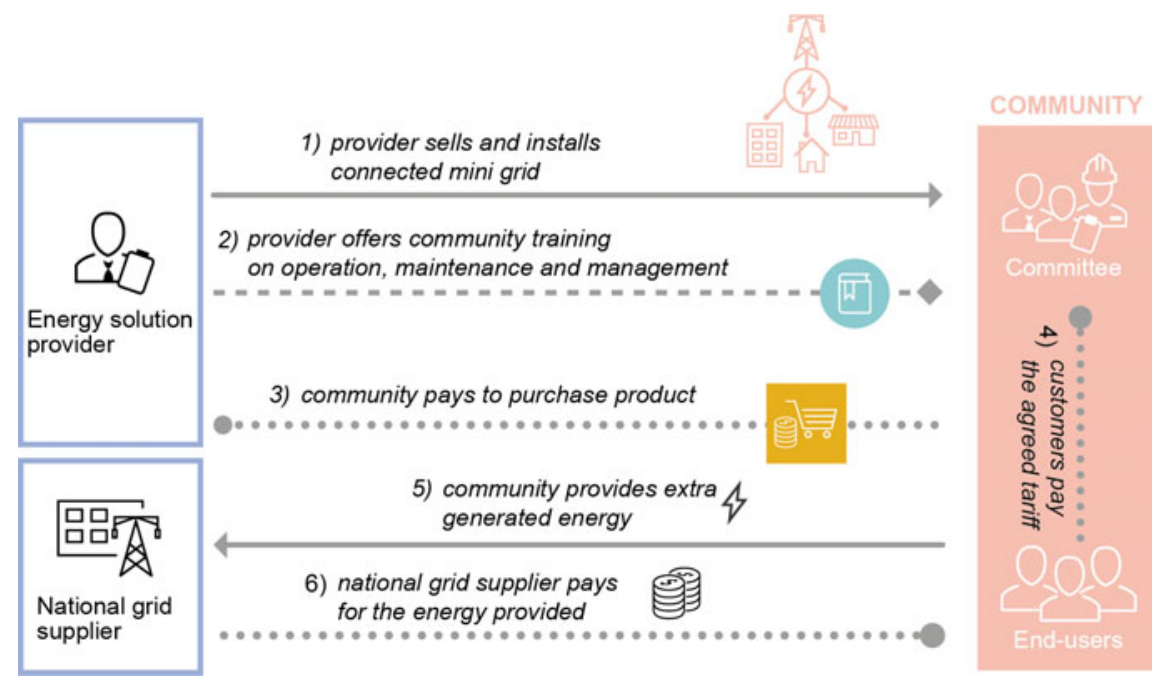

Fig. 4.12 Archetypal model 3: offering advice and training services for community-owned and community-managed connected mini-grids. Source Emili [18] 


\section{Case study:}

Ibeka/since 2013

Category: Hydropower Energy

Provider/s: Ibeka, community-managed enterprise

Customers: Local communities

\section{Location: Indonesia}

IBEKA is a non-profit organisation that provides hydro mini-grids to communities with design, installation and community organisation. IBEKA sets up a community-managed enterprise to run the system and trains it for operation, maintenance and management. The grid-connected system allows communities to sell to the national grid supplier and revenues cover operation, maintenance, loan repayments and a community fund. End users pay according to the agreed tariff: pay-per-energy consumed (metre) or an agreed amount of energy per day.

The second group of product-oriented S.PSSs (models 4 and 5) is defined as pay-to-purchase with additional services.

4. Selling mini-kits with additional services. The provider sells mini-kits with additional services, such as financing, so that customers can pay through small, flexible instalments over time. After the credit period, usually 1 or 2 years, the ownership is transferred to the customer. Operation and maintenance are the customer's responsibilities and end users receive training on system care. During the credit period, the provider offers repair services and sometimes includes extended warranties after the credit repayment.

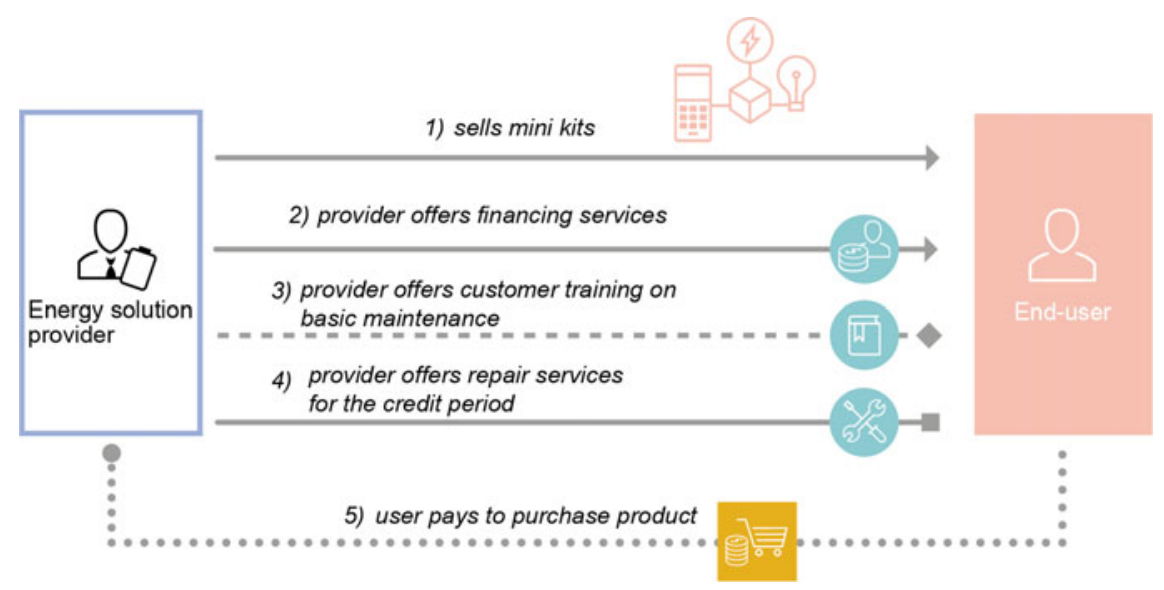

Fig. 4.13 Archetypal model 4: selling mini-kits with additional services. Source Emili [18] 


\section{Case study:}

M-KOPA/since 2010

Category: Solar Energy

Provider/s: M-KOPA, d.Light, M-PESA

Customers: Inhabitants

Location: East Africa

M-KOPA, East Africa. M-Kopa provides energy by selling solar mini-kits with lights, radio, phone charging and enabling customers to pay small, flexible instalments over time. By partnering with a technology provider (d.Light) and using the existing network of mobile money M-PESA, the company allows customers to pay an initial deposit and then processes payments via mobile money transfer. If the payment does not occur, the system gets blocked. After the credit period, the customer owns the system and benefits from free and sustainable energy provision.

5. Selling individual energy systems with additional services. The provider sells individual energy systems with or without Energy-Using Products, and includes in their offer a range of services like financial credit, customer training, installation and aftersales services such as maintenance and repair. End users pay to purchase the energy system (with or without Energy-Using Products) and the ownership is transferred to them, sometimes after the credit period.

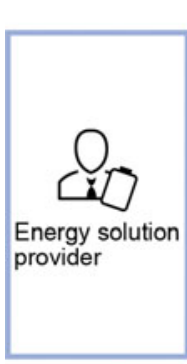

1) provider sells and installs individual energy system (with or without energy-using products) 마민ㄷㄴ +

2) provider offers financing services

3) provider offers customer training

4) provider offers maintenance and repair

5) user pay to purchase product

Fig. 4.14 Archetypal model 5: selling individual energy systems with additional services. Source Emili [18] 


\section{Case study:}

Grameen Shakti/since 1996

Category: Solar Energy

Provider/s: Grameen Shakti, local technicians

Customers: Inhabitants

Location: Bangladesh

The company offers solar home systems with a service package inclusive of end-user credit, installation, maintenance and repair, take-back services. End users, low-income households and small businesses living in rural isolated communities, can purchase the product with microcredit services and be able to repay the loan in 3-4 years. To ensure an effective aftersale service, Grameen Shakti trains women as local technicians for repairs and maintenance of systems and for assemble solar accessories such as lamps, inverters and charge controllers.

Within the use-oriented S.PSSs group, we can distinguish between pay-to-lease (archetype 6) and pay-to-rent/share/pool models (archetypes 7 and 8).

6. Offering individual energy systems (and Energy-Using Products) in leasing. The provider offers energy home systems in leasing, with or without Energy-Using Products, for an agreed period of time. The offer may or not include Energy-Using Products. Customers do not become owners of the system but have unlimited access to it (and to the Energy-Using Products) during the leasing contract. Additional services, such as repairs and maintenance, are included in the product-service package.

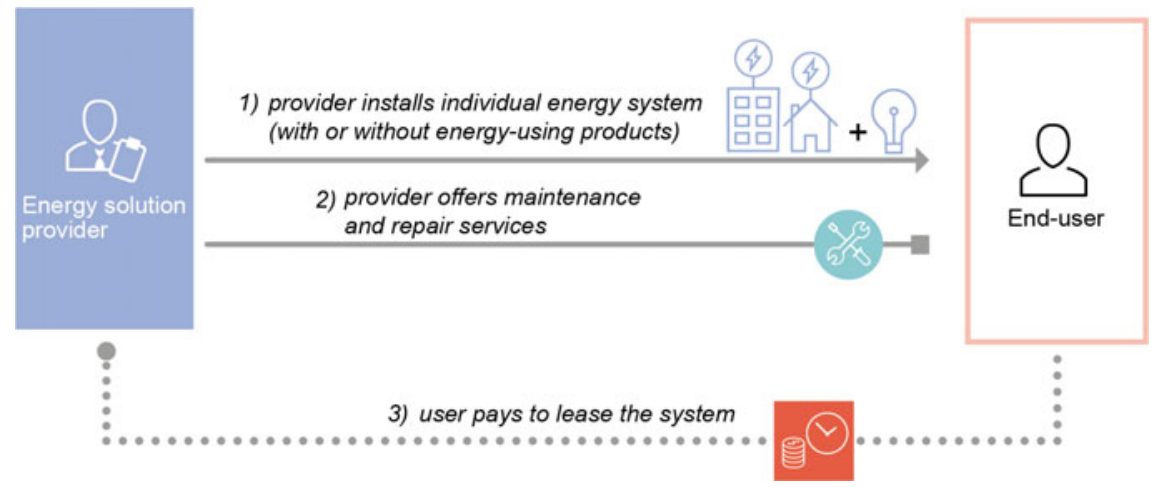

Fig. 4.15 Archetypal model 6: offering individual energy systems (and Energy-Using Products) in leasing. Source Emili [18] 


\section{Case study:}

The Sun Shines for All/since 2001

Category: Solar Energy

Provider/s: The Sun Shines for All

Customers: Inhabitants

\section{Location: Brazil}

The company offers a solar home systems package (with Energy-Using Products) on leasing by providing customers with a contract that includes installation, maintenance, battery replacement after 3 years and take-back services. Users pay an initial deposit and a monthly leasing fee according to the system size and number of lights implied. The provider, who retains the ownership of systems and appliances, trains and employs local technicians who perform maintenance, repair and take-back services.

7. Renting Energy-Using Products through entrepreneur-owned and-managed charging stations. The charging station is sold to a local entrepreneur and ownership of both the charging station and the Energy-Using Products is transferred to him/her. Training on operation and management of the charging station is provided and financing services can sometimes be included. The local entrepreneur rents out the Energy-Using Products to end users, who pay a fee when they want to use the products involved. The entrepreneur is responsible for operation and maintenance of the system and the Energy-Using Products.

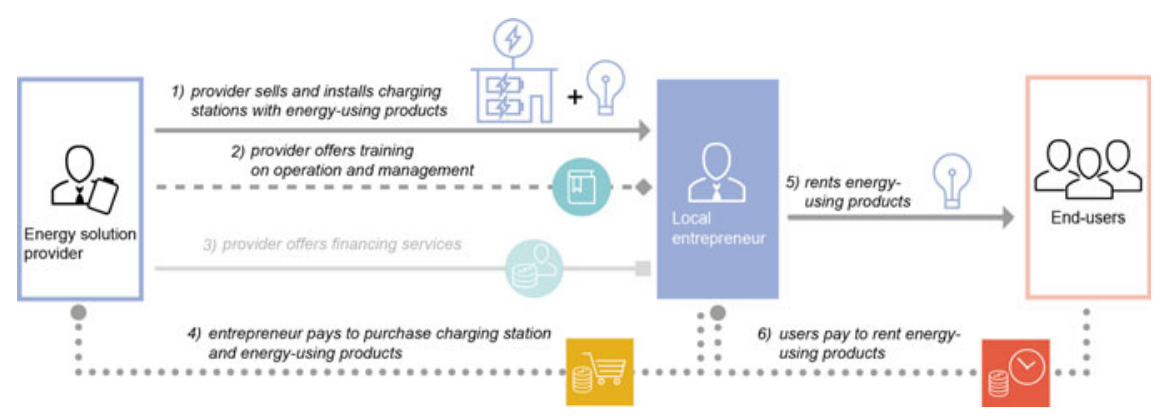

Fig. 4.16 Archetypal model 7: renting Energy-Using Products through entrepreneur-owned and entrepreneur-managed charging stations. Source Emili [18] 


\section{Case study:}

Teri/since 2008

Category: Solar Energy

Provider/s: Teri, local entrepreneurs

Customers: Inhabitants

\section{Location: India}

TERI provides charging stations for renting lanterns to rural customers in India through an entrepreneur-led model. TERI sets up micro solar enterprises in un-electrified or poorly electrified villages. A local entrepreneur, who receives training and financing, buys and manages the charging station by renting the solar lamps every evening, for an affordable fee, to the rural populace. Every household pays a nominal charge (Rs. 2-4 approx.) per day per lantern for getting it charged.

8. Renting Energy-Using Products through entrepreneur-or community-managed charging stations. The energy solution provider instals a charging station for renting out Energy-Using Products to individual users. The provider keeps ownership of the charging system and the Energy-Using Products but the management and operation is undertaken by local entrepreneurs or by the community itself, who pays a leasing fee to use the charging station. End users pay to rent Energy-Using Products when they need.

\section{Case study:}

Sunlabob/since 2000

Category: Solar Energy

Provider/s: Sunlabob, local committee

Customers: Inhabitants

Location: Laos

The company provides energy services: it leases the charging station and Energy-Using Products (lanterns) to a village committee who in turns rents the products to the individual households. The committee oversees setting prices, collecting rents and performs basic maintenance. Sunlabob retains ownership,

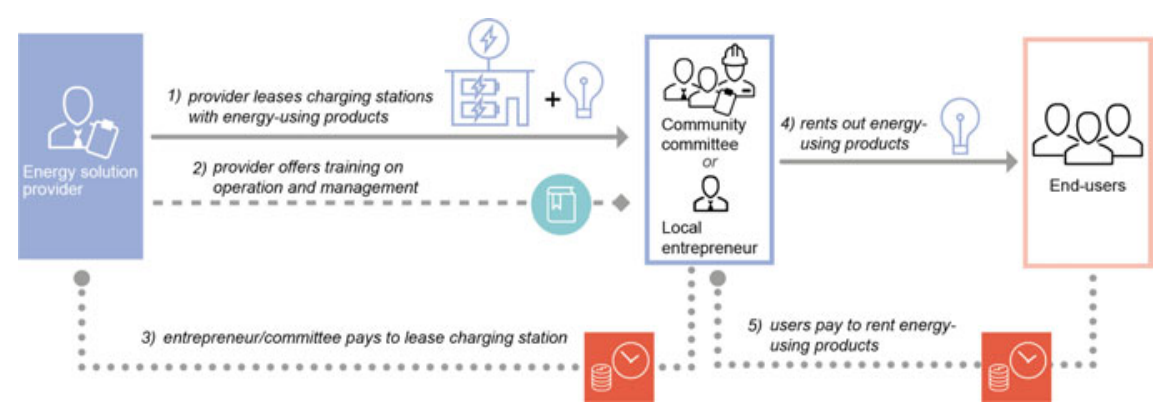

Fig. 4.17 Archetypal model 8: renting Energy-Using Products through entrepreneur or community-managed charging stations. Source Emili [18] 
maintenance responsibilities and offers training services. End users can rent the recharged lantern for $€ 0.2$ and it will last for $15 \mathrm{~h}$ of light, while the committee pays to rent the charging station (€1.5 per month).

In result-oriented models, the first group of archetypal models (9 and 10) can be defined as pay-per-energy consumed.

9. Offering access to energy (and Energy-Using Products) on a pay-per consumption basis through individual energy systems. The provider instals individual energy systems at customers' site to satisfy the electricity need. Customers pay according to the energy they consume. The provider retains the ownerships of systems and takes care of operation, maintenance and repairs.

\section{Case study:}

Gram Power/since 2012

Category: Solar Energy

Provider/s: Gram Power, local entrepreneurs

Customers: Inhabitants

Location: India

Gram Power, India. Gram Power provides energy services in rural India through the installation and operation of mini-grids. Target customers are rural communities who get connected to the mini-grid and prepay for the energy they consume. Households get smart metres installed at their home and have the possibility to prepay electricity through local entrepreneurs. The entrepreneur, in fact, purchases in bulk energy credit from Gram Power, who keeps ownership of the system, and transfer the recharge into the consumer's smart metre through a wireless technology.

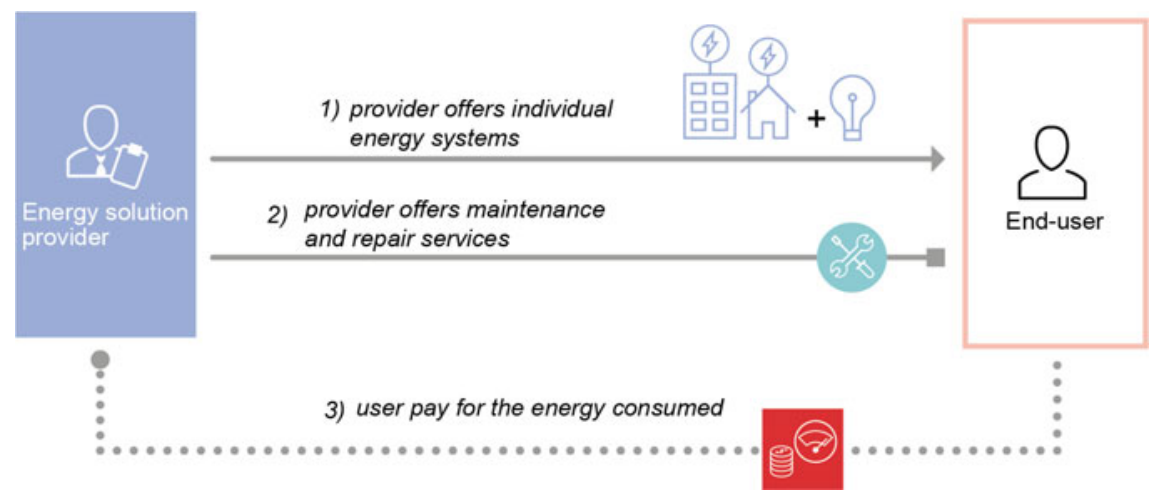

Fig. 4.18 Archetypal model 9: offering access to energy (and Energy-Using Products) on a pay-per-consumption basis through individual energy systems. Source Emili [18] 
10. Offering access to energy (and Energy-Using Products) on a pay-per consumption basis through isolated mini-grids. The provider offers energy services by installing mini-grids (with or without Energy-Using Products) at a community level. End users pay according to the energy they consume. The provider always retains the ownership of the energy system and products involved. This model can present some variations (flows 5-8): in some cases, the local community or an entrepreneur receives training and can be involved in the management, operation and maintenance of the mini-grid or fee collection. In this case, end users pay their fees to the committee or entrepreneur, who is responsible for transferring them to the energy solution provider (in this case, flow 4 would then disappear).

\section{Case study:}

OMC Power/since 2000

Category: Hydropower/Wind/Solar Energy

Provider/s: OMC power

Customers: Telecommunication companies

Location: India

OMC Power offers energy solutions to productive activities (telecom tower companies) through large stand-alone power plants running on solar, hydro, wind or hybrid, according to the specific conditions. Mobile network operators get the power plant installed on site and pay according to the energy consumed (kWh). OMC Power retains the ownership of system and provides operation and maintenance.

The second group can be named pay-per-unit of satisfaction and encompasses archetypes 11-15.

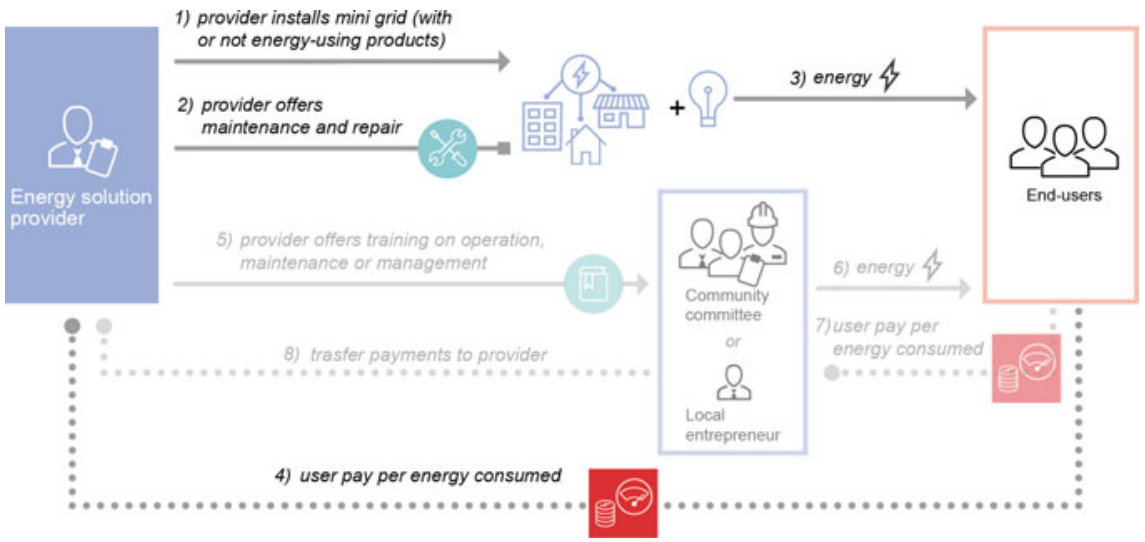

Fig. 4.19 Archetypal model 10: offering access to energy (and Energy-Using Products) on a pay-per-consumption basis through isolated mini-grids. Source Emili [18] 


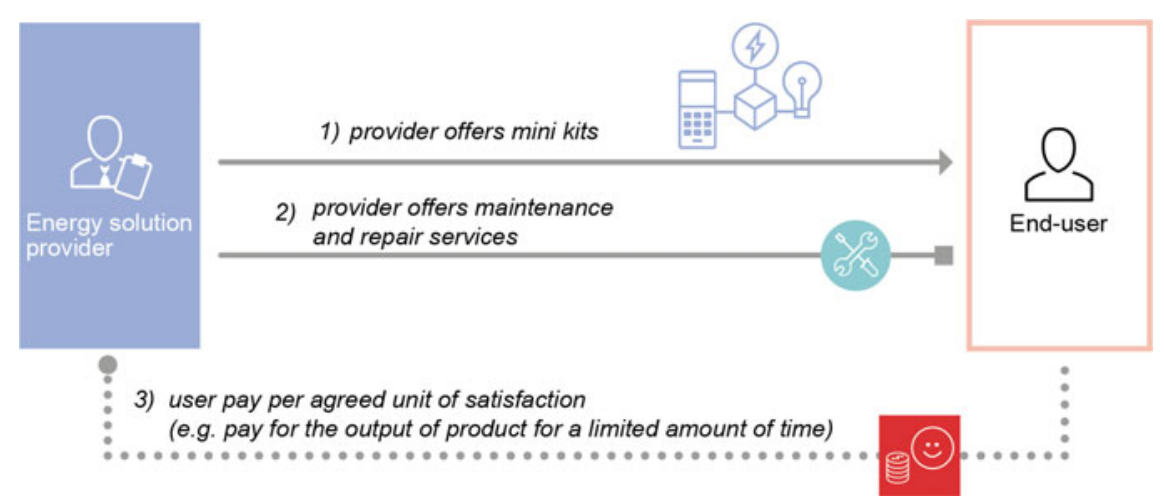

Fig. 4.20 Archetypal model 11: offering access to energy and Energy-Using Products on a pay-per-unit of satisfaction basis through mini-kits. Source Emili [18]

11. Offering access to energy and Energy-Using Products on a pay-per unit of satisfaction basis through mini-kits. The energy solution provider offers energy services through mini-kits equipped with Energy-Using Products. Users pay according to the service package they choose and the appliances they want to use (for example, they can pay to use two lights and a mobile charger for a maximum of $8 \mathrm{~h}$ a day). The provider, who retains ownership and responsibilities of the mini-kits, includes in the offer maintenance and repair services.

\section{Case study:}

Off-Grid Electric/since 2012

Category: Solar Energy

Provider/s: Off-Grid Electric, local entrepreneurs

Customers: Inhabitants

Location: Tanzania

Off-Grid Electric provides electricity services through solar mini-kits installed at customer's home. The service is tailored to users' needs and the satisfaction-based solution (two lights and a phone charger for tot hours/day) is paid by users with daily fees. Customers can choose the mini-kits with Energy-Using Products they want and upgrade with additional appliances. The starting kit includes two lights and a phone charger for $8 \mathrm{~h}$ a day. Off-Grid Electric retains ownership of systems and appliances and trains a network of local dealers for installation and customer support.

12. Offering access to energy (and Energy-Using Products) on a pay-per unit of satisfaction basis through individual energy systems. The provider instals energy home systems at the customer's site to provide electricity on a pay-per-unit of satisfaction basis. End users in fact pay a fixed monthly fee to get access to electricity or to use the included Energy-Using Products, usually for an agreed number of hours a day. The provider always retains the ownerships of the energy system (and Energy-Using Products) and takes care of maintenance and repairs. 


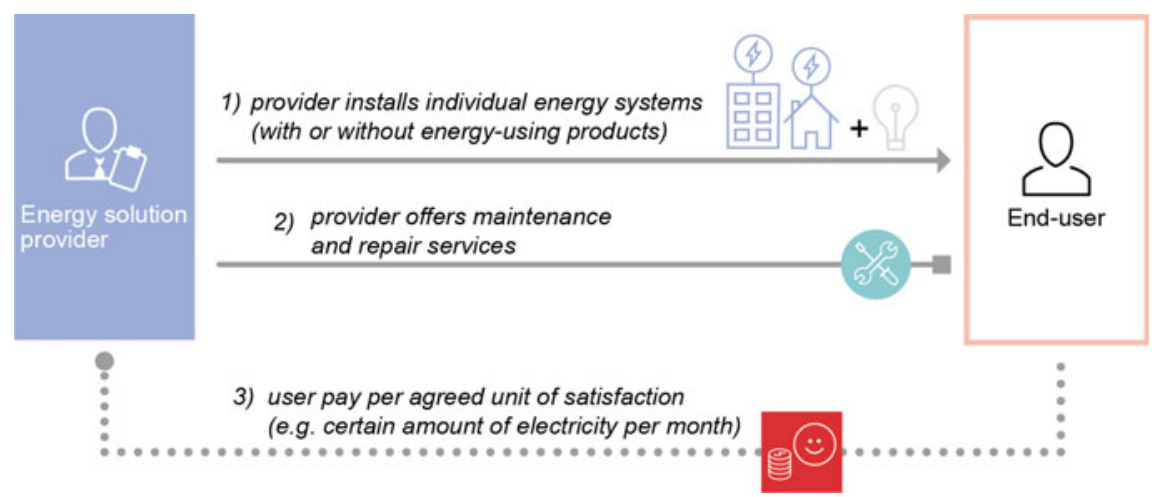

Fig. 4.21 Archetypal model 12: offering access to energy (and Energy-Using Products) on a pay-per-unit of satisfaction basis through individual energy systems. Source Emili [18]

\section{Case study:}

NuRa/since 2001

Category: Solar Energy

Provider/s: NuRa, local entrepreneurs

Customers: Inhabitants

Location: South Africa

NuRa, South Africa. NuRa provides energy through solar home systems. The company sets up an Energy Store where an entrepreneur is responsible for service provision and installation of the SHS. End users pay an initial fee (500R) and prepay a monthly fee of $61 \mathrm{R}$ that enables the connection of four fluorescent lamps and an outlet for a small black and white TV or a radio, operated on direct current $(50 \mathrm{~W}$ panel) for four hours a day. Fees, based on the unit of satisfaction agreed (X amount of electricity for $X$ hours a day), are collected through local businesses and shops. The ownership stays with NuRa, who is also in charge of maintenance and repairs.

13. Offering access to Energy-Using Products through community- or entrepreneur-managed charging stations on a pay-per-unit of satisfaction basis. The provider offers, together with training services, the charging station with Energy-Using Products to a local entrepreneur or a community committee. They in turn provide a range of energy-related services to end users, such as printing, purifying water and IT services to the local community. End users pay to get access to the Energy-Using Products (e.g. printer, photocopy or computer) on a pay-per-unit of satisfaction basis (e.g. pay-per-print or pay-per-unit of purified water). The entrepreneur/committee transfers part of the profits to the energy solution provider and is responsible for operation and maintenance of the charging station and Energy-Using Products. 


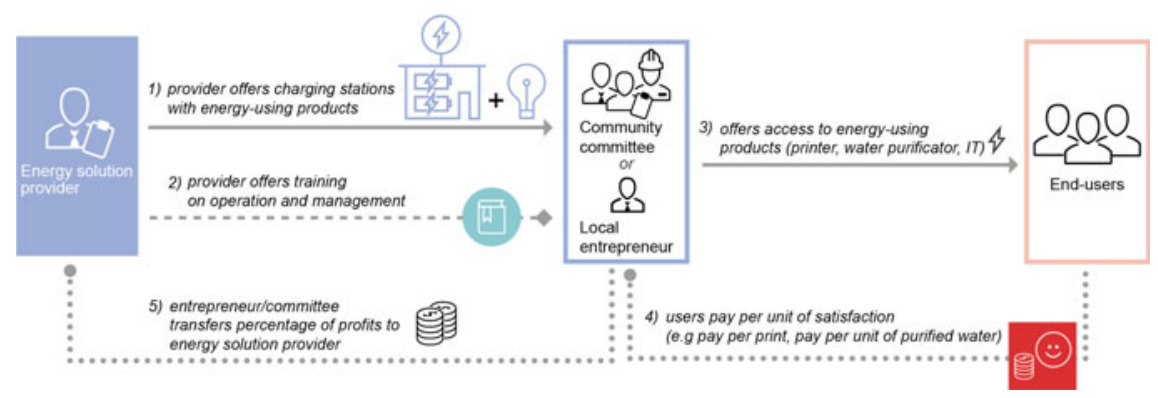

Fig. 4.22 Archetypal model 13: offering access to energy (and Energy-Using Products) on a pay-per-unit of satisfaction basis through individual energy systems. Source Emili [18]

\section{Case study:}

Solarkiosk/since 2011

Category: Solar Energy

Provider/s: Solarkiosk, local dealers

Customers: Inhabitants, local businesses

Location: Tanzania

As introduced (see paragraph 1.5) Solarkiosk targets local entrepreneurs, for the provision of energy services through charging stations. Due to the modular configuration of the station, Solarkiosk can provide a wide range of energy services such as Internet connectivity, water purification, copying, printing and scanning, etc. Customers pay for the agreed unit of satisfaction: pay-to-print, pay to get purified water, pay for Internet access, etc.

14. Offering recharging services through entrepreneur-owned and entrepreneurmanaged charging stations. The technology provider sells, with training and sometimes with financing services, the charging station to a local entrepreneur who offers recharging services to customers. End users pay to recharge their products when they need (pay-per-unit of satisfaction), for example, they pay to charge mobile phones. The entrepreneur is owner of the system and responsible for operation and maintenance.

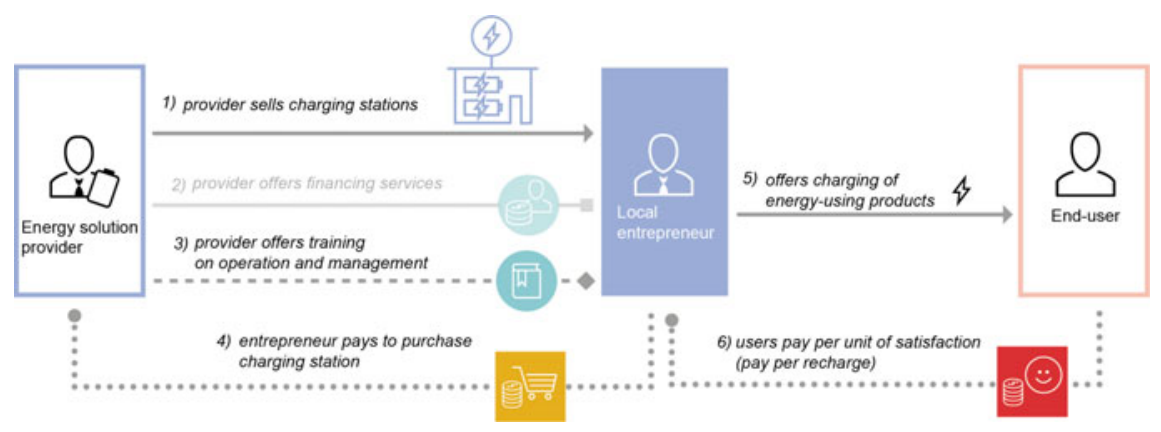

Fig. 4.23 Archetypal model 14: offering access to Energy-Using Products through community- or entrepreneur-managed charging stations on a pay-per-unit of satisfaction basis. Source Emili [18] 


\section{Case study:}

Bboxx solar energy company/since 2010

Category: Solar Energy

Provider/s: Bboxx

Customer: Households

Location: Africa, Asia

Bboxx designs, manufactures, distributes and finances solar charging stations across Africa and Asia. One of their offers targets local entrepreneurs who buy the system (with credit services) and set up a phone charging business in their communities. Bboxx trains the entrepreneur in management and operation of the power station. End users pay per unit of satisfaction, in this case to get their phones charged.

15. Offering access to energy (and Energy-Using Products) on a pay-per unit of satisfaction basis through mini-grids. The provider offers energy services by installing mini-grids (and Energy-Using Products) at a community level. Mini-grids can be connected or not connected to the main grid. End users pay to get access to a limited amount of electricity for few hours a day. The provider always retains the ownership of the system and products involved in the offer. This model can present some variations (flows 5-9): in some cases, the local community or an entrepreneur is involved in the operation, management of the mini-grid, or in the fee collection as well. In this case, end users pay the agreed tariff to the community committee or entrepreneur and payments are then transferred to the energy solution provider (in this case, flow 4 would then disappear).

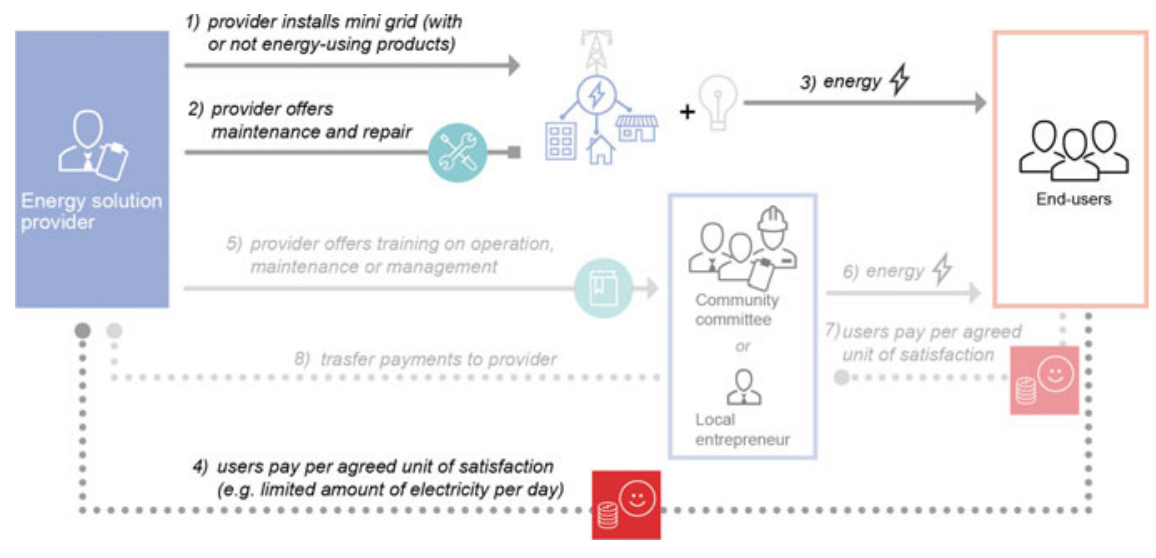

Fig. 4.24 Archetypal model 15: offering access to energy (and Energy-Using Products) on a pay-per-unit of satisfaction basis through mini-grids. Source Emili [18] 


\section{Case study:}

Husk Power Systems (HPS)/since 2007

Category: Biomass Energy

Provider/s: Husk Power

Customer: Households and companies

Location: India

Husk Power Systems, India. The company provides energy solutions by designing and installing $25-100 \mathrm{~kW}$ isolated mini-grids based on biomass power plants. A partnership with local farmers is established to provide rice husk to power the plant. Households prepay a fixed monthly fee, ranging from 2 to $3 €$, to light up two fluorescent lamps and one mobile charging station. The company retains ownership and it employs local agents for operation, maintenance and fee collection.

In conclusion, this section described a new classification system for S.PSS applied to DRE which encompasses the seven major dimensions related to both S.PSS and DRE models. Through the empirical population of the classification system with 56 case studies, 15 archetypal models that describe the existing applications of S.PSS and DRE have been identified. It should be noted that the classification system can be easily updated adding new archetypal models. For this purpose, it is important to constantly integrate the latest state-of-practice in the classification system (i.e. collect new cases, position them in the map and identify new archetypes).

The classification system can be used by companies, practitioners and experts as strategic design tool. The different applications of the classification system are discussed in Sect. 6.2.

\subsection{S.PSS Applied to DRE: Critical Factors}

Scholars from various disciplines have been studying, over the past decades, how energy solutions in low- and middle-income contexts can be effectively and successfully implemented. A set of critical factors can be identified. The sections below provide an overview of the most important of these factors. In order to illustrate them in a clear and effective way, factors have been clustered in six main groups:

- Customer: it refers to the type of target customers addressed in the S.PSS solution;

- Offer: it refers to the different types of S.PSS+DRE models;

- Products: it refers to the energy systems, renewable energy sources and EnergyUsing Products involved in the S.PSS solution;

- Services: it includes consultancy services (training, financing) and services provided during or at the end of the product life cycle (installation, maintenance and repair, product upgrade, end-of-life services);

- Payment modality: it refers to the different ways customers pay for the energy solution;

- Network of providers: it refers to the actors involved in providing the energy solution. 


\subsubsection{Customer}

The design of S.PSS+DRE models must consider the complexity of the sociocultural context where these solutions will be implemented, as well as the customers' specific requirements, such as energy demand, awareness of technology, community organisation, customers' ability to pay etc. [61].

\section{Energy demand and needs}

When designing an energy solution, one of the first key factors to be defined is the energy demand of the customer, [64] in order to be then able to choose an appropriate technology to satisfy that demand [25]. Defining customers' demand means to identify the level of peak demand, how many hours electricity is used and the types of appliances run [64]. However, future increases of demand should also be predicted. To this regard, a common practice is to consider $30 \%$ extra capacity [48]. In addition, it is important to highlight that energy solutions must be customised not only considering the energy demand, but also the specific needs of the identified target customer [10, 50, 64].

\section{Willingness to pay}

It is also crucial to ensure that the solution is affordable and matches customers' willingness to pay. Willingness to pay is strongly related to customer awareness, expectations and perceived value of energy solutions [4]. For this reason, when offering an energy solution, it is important to enhance confidence in the technology through education and training on product use and benefits [4]. Adding perceived value to the energy solution is also important to improve willingness to pay. For example, adding extra appealing features, such as mobile charging sockets, incentivises users in setting up small income generation activities [26].

\section{Ability to pay}

Another critical factor to be considered is the ability to pay of low-income customers. A common practice is to adapt payment structures that mirror existing spending patterns of the target customer [4]. Offers that allow flexible payments according to seasonality of income and cash availability are an example of strategy to be adopted to enhance affordability [25]. In this context, it is also important to mention the role played by mobile payment technologies that can allow customers to pay small incremental amounts according to their income availability, mimicking existing spending patterns for non-renewable sources (kerosene, charcoal). Another common strategy is to partner with Microfinance Institutions (MFI) and provide financing services to end users and entrepreneurs [4].

More in general, affordability is also tackled by adopting use and result-oriented S.PSS models, where customers do not pay the full value of products but instead pay to get access to energy or Energy-Using Products.

\section{Customer awareness and confidence}

One of the barriers for introducing DRE technologies in $\mathrm{BoP}^{2}$ contexts is related to the unfamiliarity or lack of awareness of renewable energy solutions. Therefore, it

\footnotetext{
${ }^{2}$ Bottom of the Pyramid (BoP) is the four billion people who live on less than say $\$ 3000$ per year, or less than $\$ 2$ a day.
} 
is important to build confidence and trust in renewable energy systems and to communicate benefits of adopting these technologies. For example, marketing campaigns operating at different levels (word of mouth, radio, roadshows, partnering with existing brands) can help to achieve this goal [4]. The introduction of S. PSS models, and especially of ownerless solutions, can be problematic due to the cultural shift required in adopting new habits and behaviours contradicting the established norm of ownership [7, 22, 37, 41, 56]. It is therefore critical to educate customers on economic and environmental benefits derived from S.PSS innovations.

\section{Recognise gender needs and address to equity}

Designing energy services for BoP customers also requires understanding how energy impacts women and men differently and how their daily tasks, responsibilities and needs influence their electricity needs [39, 50]. Thus, it is important to address the different uses of energy for men and women and to favour the integration of women in the energy solutions. For example, this can be achieved by including women in the S.PSS management or in some roles such as technicians or entrepreneurs [1]. Enhancing their income generating skills through training activities is another strategy to be taken into consideration. In fact, women are more likely to afford energy services if it can be used to generate income, such as water pumping, husking and milling or home-based enterprises [1].

\section{Involvement in the design and implementation process}

Another key success factor for DRE projects is the involvement of users and communities as early as possible in the design as well as in the implementation process $[10,13,23]$. For example, the target customers can be involved in the design process by organising focus groups and adopting participatory approaches [23]. A good example of community involvement is provided by IBEKA, an Indonesian NGO that develops community-run mini-grid projects. The NGO works closely with the community in designing a tariff structure that covers operation and maintenance. Moreover, the NGO helps in setting up a community fund. This process ensures customers involvement and support, which is vital for the success of a project [13].

\section{Differentiate the offer and address a mix of target customers}

Ensuring financial sustainability can be problematic when targeting low-income customers. Thus, addressing a mix of customers including households, commercial and productive activities may be a recipe for success [10]. This can in fact ensure a more stable customer base. For example, a company could offer solutions to productive activities (which would represent its anchor customer), and at the same time deliver more affordable energy service to lower income users in the local community [38]. An example of this approach is provided by OMC Power, which supplies energy to telecom tower companies in rural India and instals charging stations to provide energy services to nearby communities. 


\subsubsection{Energy System}

This section provides a summary of the key factors to be considered in relation to the physical elements of the energy system, including selection of renewable sources, DRE technologies and their applications.

\section{Design for local conditions}

Several factors need to be considered when the appropriate DRE technology, ranging from the environmental to the socioethical, economic, resource and regulatory aspects [31]. To begin with, the selection of a technology should reflect resource availability and be site specific [5, 35, 50, 64]. The technology should be also flexible and robust in terms of energy capacity and should consider energy demand changes and seasonality of resources [5, 6].

\section{Selection of appropriate renewable sources}

Each renewable energy source and respective technology has its own specific benefits, barriers and applications, which must be carefully considered when developing energy solutions. Main strengths and weaknesses of each type of renewable are discussed in Chap. 2.

\section{Selection of appropriate energy configuration}

Below, examples of renewable energy systems based on the presented structure and configurations (see paragraph 2.2) are provided.

\section{Mini-kits}

Mini-kits fit the configuration of distributed/stand-alone systems, and are small plug-and-play systems that include a small generator, lights, battery and other appliances such as radio or phone chargers [47]. Main strengths include easy installation, little maintenance required and low costs [47]. Because of its limited capacity, this technology is appropriate for households or small businesses, especially for scattered customers living in rural areas with a low-energy demand [13]. Usually these types of systems are coupled with mobile payments technologies, either providing microcredit or enabling pay-per-unit payments. Several examples are provided by companies such as M-Kopa, Azuri Technologies, Off-Grid Electric and Fenix International.

\section{Individual energy systems}

These are distributed/stand-alone systems that can be powered by solar, wind, hydro or biomass power and can target individual households, businesses or larger customers such as schools and productive activities. This type of technology suits especially off-grid customers and it is particularly convenient for the lack of transmission and distribution costs and for the flexibility to adapt to customers' needs [47]. However, individual systems require storage for extra-generated electricity and higher capital costs for customers (in the case the solution is not offered through use- or result-oriented S.PSS). Applications of this technology span from smaller solar home systems (e.g. Mobisol, Grameen Shakti, SELCO), to larger systems for productive activities (e.g. Redavia, OMC Power). 


\section{Charging stations}

These are decentralised/stand-alone systems that can provide charging services (batteries, lanterns) and other services such as ICT or water purification. Main advantages are related to their mobility and flexibility, which makes them suitable for off-grid or emerging settings [47]. This technology has been usually applied in use-oriented S.PSS (pay-to-rent/share/pool) and in pay-per-unit of satisfaction models, enabling even lower income customers to have access to lanterns and batteries without paying upfront costs [9]. Larger charging stations can provide energy simultaneously to productive activities (as an individual energy system) and to nearby communities through the renting of appliances. This model has been implemented by an Indian company, OMC Power, which targets telecom tower companies in rural areas and villages nearby.

\section{Isolated mini-grids}

A mini-grid fits in the category of distributed/mini-grid and is a small generation facility that provides power through a local distribution network and it is not connected to the main grid [47]. This technology varies in applications, sizes and renewable sources used. Main advantages include: flexibility and adaptability to customers' demand; suitability for productive uses of energy and for multiple types of customers; enhancement to local development and employment as it can be managed and maintained by communities [35, 51]. Isolated mini-grids suits communities that are densely populated as they require enough demand for power to be profitable [50]. Main barriers for this technology are the need for skilled personnel for operation and maintenance, management and monitoring. In addition, they sometimes require specific regulatory frameworks and high capital financing [51]. Several players are providing energy through mini-grids, adopting different types of S.PSS models.

\section{Connected mini-grids}

Connected mini-grids fit in the category grid of mini-grids, and present further advantages compared to the isolated ones. First, they allow to sell electricity to the main grid; second, they can operate at higher load factors, thus enhancing economic sustainability [38]. This DRE system is particularly convenient for communities that live close to the national electricity grid or that may be connected in the near future, allowing the integration of the two energy supply systems [2]. S.PSSs involving connected mini-grids allow providers to have an anchor customer (national grid supplier) and distribute power to communities. Some examples can be found in community-owned and community-managed systems (e.g. IBEKA and CRERAL) and in pay-per-unit of satisfaction models (e.g. Avani and Husk Power Systems).

\subsubsection{Services}

PSS solutions usually include an articulated a set of services. These can range from training and consultancy services for product use and management, to financing and microcredit services, services that aim at extending the lifespan of products 
(installation, maintenance, repair, upgrade), and end-of-life services such as recycling or take-back.

\section{Training services}

A crucial factor to enhance the success of S.PSS+DRE solutions is to integrate the energy solution with training, consultancy and advice services [49]. These services can target different stakeholders: communities who will be responsible for managing the energy system; end users who need to learn how to properly use the product/s; local entrepreneurs and local technicians, who might be involved in providing maintenance and repair services.

Community training usually focuses on providing training in operation, maintenance and management of energy systems [30]. However, it must be highlighted that the delivery of these services should take into considerations the community's structure and its existing organisation [13]. To this end, it is suggested to discuss and agree on the provision of these services together with respected individuals and community leaders [13]. The involvement of local partners to provide training, such as NGOs or cooperatives that can deliver training in the local language, represents another potentially effective strategy $[13,23]$.

On the other hand, end-user training is crucial in order to ensure that customers understand capabilities and limitations of energy systems and optimise energy consumption (to reduce risk of blackouts and system failures). In fact, technical problems are often caused by systems' overuse, related to the lack of understanding of their limitations [10, 33]. This type of training services can be provided during system installation or through regular visits of technicians [33].

If the S.PSS+DRE solution also involve local entrepreneurs, it is important to empower them with training services. To this regard, coupling technical and business training with technologies that allow income generation can help fostering local economies and economic sustainability [45].

Establishing a network of local technicians who can provide prompt maintenance and repair services represents a fundamental aspect to ensure good after-contract services [23]. To this end, it is important to provide appropriate training to these technicians, focusing first on the most recurring technical challenges [23]. For example, Grameen Shakti (Bangladesh) trains women for performing repairs, maintenance and assembling of solar accessories, ensuring an effective after-contract service.

\section{Microcredit to end users and entrepreneurs}

Providing financial service to customers and entrepreneurs is an essential element to be integrated in solutions that targets BoP markets [32]. Microcredit services can be offered to customers with low or irregular income, and to local entrepreneurs who want to partner up with the energy provider. These services can be delivered in partnership with a Microfinance Institution (MFI) or other financial institutions. Crucial aspects to be considered when delivering these services are: willingness and ability to borrow; size of the down payment and monthly payments; and credit history and financing environment of target customers [16]. 


\section{Installation}

Providing installation as part of the S.PSS package is important in order to prevent that systems are installed improperly or wrong components are used [28]. Delivering installation services also provides an opportunity to train local technicians and end users [15].

\section{Maintenance and repair}

When providing a S.PSS solution, manufacturers have an economic interest to extend as much as possible the lifespan of the energy system and Energy-Using Products, in order to keep their costs as low as possible. For this reason, ensuring products long lifetime is essential to avoid system failures and improper repairs by end users, but also to reduce costs incurred by the provider. This is a crucial aspect, since it has been shown that the lack of a proper maintenance and repair network represents the main factor influencing the failure of community-managed systems. However, providing maintenance and repair can be challenging and expensive, in particular in rural and sparsely populated areas [4]. Common strategies include training local technicians in order to optimise service delivery, and using existing local infrastructures to store spare parts. For example, DESI Power (India), trains local entrepreneurs to operate and maintain power plants and adopts a standardised technology that does not require specialised skills.

\section{Product upgrades}

Product upgrading can be provided by offering modular and upgradable solutions, for example, allowing users to add elements over time (e.g. more lights, TV or radio). In this way, changes in consumers' wants and needs can be met modifying or upgrading the systems instead of manufacturing new products [42]. This is especially relevant for those S.PSSs in which the provider keeps the ownership and responsibility over the energy system and Energy-Using Products.

Also, replacing technologically obsolete components and products (e.g. batteries) can help optimising energy consumption. Again, this is aligned with the economic interest of providers who deliver result- and use-oriented S.PSSs.

\section{Use optimisation services}

The use optimisation of PSS can be provided as a service e.g. training on product/s use; or as technological solution, e.g. smart device to check SHS conditions. In the case of products which require energy in use, their use optimisation can reduce the use of resources (energy) and potentially toxic emissions. For example, Bboxx (Asia and Africa) provides SHS connected to its platform, which allows BBoxx to monitor energy consumption and the performance of the systems. These data are used to optimise products use and extend the life of the batteries. So forth, product use optimisation service can entail a gain sharing among the customer (reduced cost to reach her/his satisfaction due to low-energy use), the provider (reduced cost on energy and product replacement) and the environment (reduced use of resources and/or energy and materials). 


\section{End-of-life services}

Providing services to ensure that the energy system and the Energy-Using Products are collected to be reused or remanufactured at the end of their lifespan is a key factor to ensure environmental sustainability [41]. In addition, as said before, when providing S.PSS solutions, manufacturers are economically incentivised in doing that, since they keep ownership of the equipment/products involved. End-of-life services can be provided through strategic partnerships with local actors which can collect broken equipment or expired batteries [23]. A key factor also relates to the design of the products involved in the S.PSS, which should be easily disassembled or designed to facilitate reuse and remanufacturing.

\subsubsection{Network of Providers}

PSS solutions usually involve a variety of different stakeholders in designing, producing and delivering the various element of the solution. The text below provides insights on the potential roles that different stakeholders can play in $\mathrm{S}$. PSS\&DRE solutions.

\section{Private enterprise}

Private enterprises can cover a variety of roles and be directly involved in the design, manufacturing and in the provision of services. Small-scale companies have the advantages in terms of proximity to customers, while larger scale enterprises may be more likely to ensure financial viability [33]. Independently from the size and structure of private companies, ensuring a strong local representation is considered a key success factor (Asian Development Bank; [23]). This can be achieved, for example, by involving agents that are part of the target communities and building a network of dealers and service personnel at a local context. In this context, existing networks related to other products (e.g. farms machinery, generators, telecommunications etc.) can be used to deliver the energy solution [24]. An example of this is the Kenyan company M-Kopa, which uses existing network of shops and retailers from its partner Safaricom to provide their energy solution.

\section{Technology manufacturer}

A key role in S.PSS solutions is covered by manufacturers. As already emphasised in Sect. 3.3 S.PSS Sustainability benefits, manufacturers should be part of the S. PSS solution in order to fully exploit the sustainability potentials offered by this model. In other words, manufacturers should keep ownership and/or responsibility over (some of) the life cycle stages of their products (energy system and/or Energy-Using Products). In fact, in these cases manufacturers have an economic interest in extending as much as possible the lifespan of their products, in order to reduce maintenance, repair and disposal costs, as well as the costs of manufacturing new products. For example, Kamworks, a Cambodian company, designs and manufactures solar home systems and lanterns and offers these products with a package of services: product-related services (maintenance, training) or advice and consultancy are offered when products are sold; in the use-oriented offer, energy 
systems and Energy-Using Products are provided on renting or leasing, thus including all the required maintenance, repair and take-back services.

\section{Community}

The involvement of communities is a key factor in the success of energy solutions in BoP contexts [60]. However, it is important to highlight that they should be involved not only as consumers, but also as partners in the development and provision of the energy solution (ibid.). In fact, when directly involved in providing their own energy, communities have a strong incentive in operating and maintaining systems in a sustainable way [13]. The involvement should take place as soon and as much as possible from project implementation to the organisation of the energy solution [48]. To this end, a potential strategy is to involve established cooperatives or organisations at a village level in order to plan the energy solution according to the existing local organisational structure. However, community involvement could be hindered by their lack of technical and business skills. In these cases, communities, or their representatives, need to be properly trained, especially if they are involved in managing/delivering some aspects of the energy solution [13]. These training activities can be facilitated by partnering up with local NGOs.

\section{Local entrepreneur}

Local entrepreneurs are individuals, either with existing business activities or not, who can be involved in providing energy solutions or who can perform specific tasks such as maintenance services or fee collection. Local entrepreneurs might play an important role, especially when energy services have to be delivered in scarcely populated areas. For example, they can perform some services such as maintenance and repair or supporting product distribution. However, local entrepreneurs might usually need to be assisted with access to financing and microcredit [29, 50]. In fact, entrepreneurs may not be able to cover initial investments for setting up an energy business. In addition, it is important to consider that, depending on the activities the entrepreneurs have to perform, appropriate training should be provided [50].

\section{Cooperative}

Cooperatives are organisations composed by members that come together for a common purpose and can operate in various sectors (e.g. agriculture). They can provide energy solutions or play a role in partnership with the energy provider (similarly to what local entrepreneurs can do). The involvement of cooperatives is strategic because they have direct relationships with their members, they are characterised by self-regulatory forces and promote equal participation [63]. For example, successful cases are found in Nepal and Brasil, where cooperatives manage connected mini-grids and provide powers to local communities (e.g. CRERAL). Other important roles for cooperatives are: to provide financial support to end users and local entrepreneurs, as partners for the distribution of energy products or to support training, awareness campaigns [23].

\section{Non-Governmental Organisation (NGO)}

NGOs can be defined as mission-driven organisations that aim to achieve social or environmental objectives. The role of NGOs can be crucial in delivering S.PSS 
applied to DRE as they can be directly involved in providing (elements of a) solutions or can represent a strategic partner. For example, some NGOs such as Practical Action in Peru and Avani in India design and implement energy solutions at a community level and train villages on operation and maintenance of mini-grids. Their knowledge of the local context and their strong relationships with communities make NGOs a strategic partner in S.PSS+DRE solutions [24].

NGOs can also be involved in supporting some activities such as raising awareness, market research, or assisting in the distribution of products [3, 23]. In addition, through their network of donors and access to subsidies, NGOs can also facilitate customers' financing [38]. Also, they can help in selecting and training local entrepreneurs that will deliver energy solutions. For example Solar Sisters, an African NGO, partners with manufacturers such as d.Light and Angaza Design and empowers women by distributing solar technology through a network of franchisees. Solar Sister provides the women with a 'business in a bag', a start-up kit of inventory, training and marketing support.

\section{Microfinance Institution (MFI)}

Microfinance Institutions (MFI) are credit organisations that can play a key role in S. PSS+DRE as strategic partners for financing customers and entrepreneurs. For example, SELCO (Sri Lanka) offers tailored products and financing services to its clients by facilitating customers getting financed through its partners. SELCO partners with SEED (Sarvodaya Economic Enterprise Development Services) and while it focuses its expertise on providing high-quality services in installation and maintenance of systems, the MFI takes care of loans and repayments. When involving a MFI as financing partner, some key aspects must be taken into consideration. First, training and awareness must be provided to MFI staff in order to allow them to understand technology options and design credit offers accordingly [23]. Second, good communication and cooperation between MFIs and technology providers is essential in order to ensure fee collection and continuation of payments [34].

\section{Public entities and governmental institutions}

Other actors from the public sector (e.g. public utilities) might be involved in providing energy solutions or can be engaged as partners to cover some aspects of the S.PSS offer, such as financing or regulatory support. When large-scale utilities or ESCOs (Energy Service Companies) are responsible for providing energy services, they can cover all aspects from financing to marketing, to customer education and maintenance services [25]. This can be achieved thanks to their extensive experience, financial resources and technical capabilities [33, 48]. However, a key factor that should be considered in these cases is to ensure local presence and assistance to customers, for example, by training local entrepreneurs and technicians to provide maintenance and fee collection [33, 48].

In other cases, public entities can be partners for the project's financing, the provision of subsidies to customers or the creation of supporting policies. In fact, the regulatory aspects play an important role in facilitating or limiting the diffusion of S.PSS+DRE solutions, and governmental entities can contribute in creating appropriate protective policies and regulations [39]. 


\subsubsection{Offer}

As described in Sect. 4.4, S.PSS applied to DRE: a new classification system and 15 archetypal models, six types of S.PSS applied to DRE can be defined, and 15 Archetypal Models distinguish different types of S.PSS+DRE offers (see Sect. 4.4.2). In this section, main critical factors for each type of S.PSS offer are discussed.

\section{Product-oriented: Pay-to-purchase}

In this type of S.PSS and DRE, the ownership of energy system and appliances is transferred to the customer with additional services. This payment structure (pay-to-purchase) is usually adopted for small individual energy systems and mini-kits as investment costs are relatively low and the purchase includes the additional services provided [13]. In fact, access to financing is crucial when customers pay to purchase systems, because affordability is a critical aspect to be addressed [4, 10]. Companies offering microfinancing options (e.g. M-Kopa, Mobisol, Grameen Shakti, SELCo, Azuri Technologies, Fenix International etc.) have addressed this issues by spreading payments over a credit period.

When this model is applied to mini-grids, the S.PSS solution involves community-owned and community-managed systems and it usually implies in-kind contributions from the community or the involvement of subsidies/donations.

In terms of environmental sustainability, product-oriented S.PSSs present in general a lower potential compared to use and result-oriented offers [52, 53]. As highlighted before, S.PSS models must be properly designed to be a sustainable alternative to traditional business models. In this case, providers can offer advice on product use and training on energy system operation, aiming at optimising energy consumption. Additional services that aim at extending lifespan of products such as maintenance, and repair should be provided. Additionally, end-of-life services are crucial to ensure safe disposal of polluting and dangerous components, such as batteries [1,50]. Companies such as Grameen Shakti and SELCO are succeeding in providing a complete service package, from installation to financing, maintenance and recycling of individual energy systems.

\section{Use-oriented: Pay-per-time of use}

In use-oriented S.PSSs two types can be distinguished: pay-to-lease and pay-to-rent/share/pool. With leasing, customers pay a regular fee (e.g. pay-per-month) for an individual and unique access to products. Leasing models should consider the ability to pay of customers, as users with unstable income may not be willing to sign for monthly payments if they are not sure they can afford it.

With renting, customers pay for the use of products for shorter periods of time (e.g. pay-per-hour, pay-per-day) and sometimes simultaneously with other users (pooling model). The ownership of equipment/products (and the responsibility for maintenance, repair, disposal etc.) is retained by providers. This model mimics the existing spending patterns of lower income customers (with kerosene) and customers pay only when they need or when they can afford the product [9]. 
These types of S.PSSs might trigger some rebound effects [8]. The impact on customers' behaviour should be considered when introducing ownerless solutions such as leasing and renting models. In fact, if the user does not own the product, he/ she may adopt careless behaviours and misuse and mishandle of products can reduce their lifespan. Thus, products should be properly designed to be used and shared amongst different users [42]. In fact, since providers retain the products ownership, it is in their economic interest to have products that are long-lasting (easy to be maintained, repaired, upgraded), easy to remanufacture and easy to recycle.

Another aspect is related to the awareness of economic benefit emerging from adopting a use-oriented S.PSS. Customers may lack understanding about life cycle costs [59] and therefore prefer solutions where they become owners of the products.

\section{Result-oriented: Pay-per-energy consumed}

In result-oriented S.PSSs, consumption-based offers involve the provider retaining ownership of products (energy systems and Energy-Using Products) and the customer paying to get energy on a $\mathrm{kWh}$ basis.

Some issues related to this type of payment structure are related to the ability to pay of lower income customers and the process of fee collection [33, 46]. An effective approach is to monitor customers and conduct daily/weekly visits to ensure payments, such as DESI India and Gram Power solutions which involve local entrepreneurs working in villages and regularly visiting households. Another option is to use prepayment technologies to limit demand and avoid overconsumption [33]. However, when adopting this type of S.PSS, limited capacity of DRE systems must be considered. In fact, this type of offer may result in overconsumption and system failures, especially if customers are not aware of limits of renewable energy sources and technologies.

Some solutions allow extra capacity to be added according to energy demand. Shared Solar, for example, provides solar-based isolated mini-grids in Mali. When demand grows, additional PV panels are added to the generator and customers prepay for the energy they consume using mobile payments.

\section{Result-oriented: Pay-per-unit of satisfaction}

Another type of S.PSS applied to DRE has been defined as 'Pay-per-unit of satisfaction' and encompasses those models where customers pay to get access to energy and Energy-Using Products according to the agreed satisfaction unit. This S. PSS includes several payment structures:

- pay-per-recharge: pay a fixed cost for recharging an Energy-Using Product (e.g. a lantern or a phone).

- pay-per-lux: pay a fixed cost for an agreed level of luminance of a building.

- pay-per-print or Internet connectivity: pay a fixed amount to use Energy-Using Product/s.

- pay-per-energy service package: pay a fixed fee to have access to Energy-Using Products and a limited amount of energy.

In the case of pay-per-energy service package, customers might pay a fixed tariff according to the agreed result or according to the limits of the power generation [13]. In the first case, fees can be set according to different levels of consumption, 
determined on existing or desired appliances and the regularity of their use [27]. For example, customers pay to use few lights, a mobile charger and TV for a certain amount of time per day. In the second case, customers pay to have a limited agreed amount of energy per day. Here limiting devices such as smart metres can be used to ensure the energy provision is fixed and to avoid system overload. Some companies such as Off-Grid Electric in Tanzania are providing these unlocking systems to ensure payments are met. Others, such as Mera Gao Power in India, involve local entrepreneurs to collect weekly fees and ensure that the system automatically locks according to its generation capacity.

The inclusion of energy-efficient products is particularly crucial for this type of S.PSS and its application in low-income contexts [47]. Some studies highlighted that it is necessary to include energy-efficient components with the energy systems and ensure that users are lifted from the responsibility of replacing them [47]. The provider retains responsibilities for managing and operating on the products involved, avoiding that customers influence efficiency and capacity of the energy system. It has been argued that fixed tariffs do not encourage customers in conserving energy and avoiding overconsumption [2]. For this reason, it is crucial to ensure this aspect is tackled through technology (e.g. use of locking meters, inclusion of efficient Energy-Using Products) and through customer education and training. As discussed for use-oriented S.PSSs, solutions must be properly designed to deliver the sustainability potential and to provide a more environmentally friendly alternative to traditional business models.

Some barriers are also related to the applications of this type of S.PSS. The main cultural barrier is related to the adoption of ownerless solutions [22, 37, 41, 56]. In addition, in pay-per-unit/result models, the final user may feel less responsible for the good use of the system [33] and may tend to adopt careless behaviours [8]. In addition, as mentioned in use-oriented S.PSS, lacking understanding about life cycle costs may steer the choice towards solutions where they become owners of the products.

\section{Mixed offers}

Combining S.PSS offers can strategically mix payment structures for different customer segments. For example, lower income household can pay a fixed amount for a limited service (pay-per-unit of satisfaction) whereas productive activities or higher income customers can pay-per-energy consumed (kWh). This approach can ensure financial viability of S.PSSs [10] and provide customer's satisfaction according to specific needs of each target group. An example is provided by OMC Power, an Indian company that targets productive activities (telecom tower companies) on a pay-per-consumption basis and communities through a use-oriented model (renting of appliances).

\subsubsection{Payment Channels}

Different payment methods and channels can be adopted in S.PSS+DRE models. These include cash and credit, mobile payments, scratch cards and energy codes, 
in-kind contribution, fee collection and remote monitoring as an activity supporting payment.

\section{Mobile payments}

The wide adoption of mobile services and the great diffusion of mobile phones provide an opportunity to use this technology for payment purposes [12]. This type of payment tackles some of the main barriers of energy solutions at the BoP: revenue collection and affordability for customers [43]. In addition to representing represents an innovative way for low-income people to have access and pay for energy services, the integration of payments in mobile phones can also offer remote control of products' performances and consumption [43]. Several companies have adopted mobile solutions to collect (e.g. M-Kopa, Azuri Technologies, Mobisol and Shared Solar).

\section{Scratch cards and energy credit codes}

Scratch cards can be used to deploy energy credits in forms of unique codes that allow customers to prepay the electricity provision and unlock the energy system. This payment method can be very convenient for prepayment of systems and enables flexibility of payments, allowing users to mimic the patterns of airtime purchases [4, 23]. The involvement of local vendors and entrepreneurs in distributing prepaid cards is an important factor to be considered. Azuri Technologies, for example, sells mini-kits with a mobile credit service: after paying an installation fee, users purchase a scratch card at local vendors each week and adds credit to their unit via mobile phone.

\section{Fee collection}

The definition of a suitable fee collection scheme is extremely important as it can influence customers' willingness to pay [13]. To this end, an effective strategy is to adapt collection schemes to local income patterns (e.g. the seasonal income of farmers and rural customers) [33]. Ensuring local representation for the collection of payments, for example, involving local technicians who can perform regular visits to customers, represents another important factor [23]. For example, Mera Gao Power (Indian provider of mini-grids) involves local technicians who have existing relationships with customers and who visit households weekly to collect payments.

\section{In-kind contribution}

Another type of payment method can be in-kind contribution in the form of labour or resources produced by the end user or the community. Communities may be involved in providing labour for mini-grids works and construction [24]. This approach has also the added value of increasing the sense of ownership from the end users and is it critical to ensure a sustainable operation and maintenance [48]. Another example of including end users is to involve farmers who can provide biomass to generate power and have a reduction on their tariff [29].

\section{Remote monitoring}

Remote monitoring and metre reading are activities that support payment. Metres can be used to monitor energy consumption, disconnect non-paying customers and 
load supply according to the contract agreement. Metres are also useful to incentivise energy consumption reduction and efficiency by allowing customers to have accurate record of their consumption.

The simplest option is to instal normal metres, but in these cases reading must be performed periodically (e.g. by technicians). Another option is to use smart metres and prepayment. In this way, the management of energy loads and payments can then be done remotely so that the problem of reading, billing and collecting can be solved [4, 43].

\section{References}

1. Adams S, Annecke W, Blaustein E, Jobert A, Proskurnya E, Nappez C et al (2006) A guide to monitoring and evaluation for energy projects. HEDON, 1-98

2. Africa Renewable Energy Access Program (AFREA) (2012) Institutional approaches to electrification - the experience of rural energy agencies in Sub-Saharan Africa. The World Bank Group, Washington DC

3. Bairiganjan S, Cheung R, Delia EA, Fuente D, Lall S, Singh S (2010) Power to the people. Investing in clean energy for the base of the pyramid in India. CDF, New Ventures, and WRI. Taramani

4. Bardouille P (2012) From gap to opportunity: business models for scaling up energy access. IFC World Bank Group, Washington DC

5. Barnett A (1990) The diffusion of energy technology in the rural areas of developing countries: a synthesis of recent experience. World Dev 18(4):539-553

6. Biswas WK, Bryce P, Diesendorf M (2001) Model for empowering rural poor through renewable energy technologies in Bangladesh. Environ Sci Policy 4:333-344

7. Ceschin F (2013) Critical factors for implementing and diffusing sustainable product-Service systems: insights from innovation studies and companies' experiences. J Clean Prod 45:74-88

8. Ceschin F (2014) Sustainable product-service systems. Between strategic design and transition studies. PoliMI Springer Briefs. Springer, UK

9. Chaurey A, Kandpal TC (2009) Solar lanterns for domestic lighting in India: viability of central charging station model. Energy Policy 37:4910-4918

10. Chaurey A, Krithika PR, Palit D, Rakesh S, Sovacool BK (2012) New partnerships and business models for facilitating energy access. Energy Policy 47:48-55

11. Correa HL, Ellram LM, Scavarda AJ, Cooper MC (2007) An operations management view of the service and goods mix. Int J Oper Prod Manage 27(5):444-463

12. Craine S, Mills E, Guay J (2014) Clean energy services for all: financing universal electrification. Sierra Club, San Francisco

13. Cu Tran Q (2013) ASEAN guidelines on off-grid rural electrification approaches. ASEAN Centre for Energy, Indonesia

14. Da Costa J, Diehl JC (2013) Product-service system design approach for the base of the pyramid markets: practical evidence from the energy sector in the Brazilian context. In: Micro perspectives for decentralized energy supply

15. Da Silva IP, Hogan E, Kalyango B, Kayiwa A, Ronoh G, Ouma AC (2015) "Innovative energy access for remote areas: the LUAV-light up a village" Project. In: Groh (ed) Decentralized solutions for developing economies - addressing energy poverty through innovation. Springer, UK

16. Energy Sector Management Assistance Program (ESMAP) (2001) Best practice manual. Promoting decentralized electrification investment. UNDP/The World Bank

17. Emili S, Ceschin F, Harrison D (2016) Product-Service Systems applied to Distributed Renewable Energy: a classification system and 15 archetypal models. Energy for Sustainable Development 32, 71-98 
18. Emili S. (2017) Designing Product-Service Systems applied to Distributed Renewable Energy in low-income and developing contexts: A strategic design toolkit. PhD Thesis, Brunel University London

19. Friebe CA, Flotow P, Von Täube Fa (2013) Exploring the link between products and services in low-income markets - evidence from solar home systems. Energy Policy 52:760-769

20. Gaiardelli P, Resta B, Martinez V, Pinto R, Albores P (2014) A classification model for product service offerings. J Clean Prod 66:507-519

21. Gebauer H, Friedli T (2005) Behavioural implications of the transition process from products to services. J Bus Ind Mark 20(2):70-80

22. Goedkoop MJ, van Halen CJG, te Riele HRM, Rommens PJM (1999) Product service systems, ecological and economic basics. paper, Dutch ministries of Environment (VROM) and Economic Affairs (EZ)

23. Gradl C, Knobloch C (2011) Energize the BoP! Energy business model generator for low-income markets. A practitioners' guide. Endeva, Berlin

24. Gunaratne L (2002) Rural energy services best practices. USAID-SARI/Energy Program

25. Hankins M, Banks D (2004) Solar photovoltaics in Africa-experience with financing and delivery models. UNDP/GEF, New York

26. International Finance Corporation (IFC) (2011) The off-grid lighting market in Sub-Saharan Africa: market research and synthesis report. IFC/The World Bank, Washington DC

27. International Renewable Energy Agency (IRENA) (2012) Renewable energy technologies: cost analysis series. Solar photovoltaics. International Renewable Energy Agency, Abu Dhabi

28. International Solar Energy Society (ISES) (2001) Rural energy supply models. German Federal Ministry for the Environment, Nature Conservation and Nuclear Safety (BMU)

29. Iyer C, Sharma S, Khanna R, Laxman A (2010) Decentralized Distributed Generation for an inclusive and low carbon economy for India. India Infrastructure Report 2010, Infrastructure Development in a Low Carbon Economy

30. Jain S, Koch J (2009) Social entrepreneurship in the provision of clean energy: towards an organizing framework of market creation for underserved communities. Conference on Social Entrepreneurship, NY

31. Kishore VVN, Jagu D, Gopal EN (2013) Technology choices for off-grid electrification. In: Bhattacharyya (ed) Rural electrification through decentralised off-grid systems in developing countries, green energy and technology. Springer, London

32. Koch JL, Hammond AL (2013) Innovation dynamics, best practices and trends in the off-grid clean energy market. J Manage Glob Sustain 2:121-139

33. Lemaire X (2009) Fee-for-service companies for rural electrification with photovoltaic systems: the case of Zambia. Energy Sustain Dev 13:18-23

34. Lemaire X (2011) Off-grid electrification with solar home systems: the experience of a fee-for-service concession in South Africa. Energy Sustain Dev 15:277-283

35. Lemaire X (n.d.) Distributed generation: options and approaches. Sustainable Energy Regulation and Policy for Africa. REEEP and UNIDO

36. Mandelli S, Mereu R (2014) Distributed generation for access to electricity: "Off-main-grid" systems from home-based to microgrid. In: Colombo E et al (eds) Renewable energy for unleashing sustainable development. Springer, Heidelberg, pp 75-97

37. Manzini E, Vezzoli C, Clark G (2001) Product service systems: using an existing concept as a new approach to sustainability. J Des Res 1(2)

38. Martinot E, Chaurey A, Lew D, Moreira JR, Wamukonya N (2002) Renewable energy markets in developing countries. Ann Rev Energy Environ 27:309-348

39. Modi V, McDade S, Lallement D, Saghir J (2005) Energy services for the millennium development goals of the international bank for reconstruction and development. The World Bank, United Nations Development Programme, Washington DC

40. Mont O (2004) Product-service systems: Panacea or myth? PhD Dissertation. IIIEE, University of Lund, Sweden

41. Mont O (2002) Clarifying the concept of product - service system. J Clean Prod 10:237-245

42. Niinimäki K (2014) Sustainable consumer satisfaction in the context of clothing. In: Vezzoli et al (eds) Product-service system design for sustainability. Springer, Heidelberg 
43. Nique M, Arab F (2012) Sustainable energy \& water access through M2M connectivity. Report, GSMA Mobile for Development, London

44. Penttinen E, Palmer J (2007) Improving firm positioning through enhanced offerings and buyerseller relationships. Industrial Marketing Management, 36(5), 552-564

45. Practical Action (2016) Poor People's Energy Outlook - National Energy access planning from the bottom up. Practical Action Publishing Ltd. Rugby, UK

46. Roach M, Ward C (2011) Harnessing the full potential of mobile for off-grid energy. GSMA and IFC, London

47. Rolland S (2011) Rural electrification with renewable energy. Technologies, quality standards and business models. Alliance for Rural Electrification, Brussels, Belgium

48. Rolland S, Glania G (2011) Hybrid mini-grids for rural electrification: lesson learned. Alliance for Rural Electrification, Brussel, Belgium

49. Schillebeeckx SJD, Parikh P, Bansal R, George G (2012) An integrated framework for rural electrification: Adopting a user-centric approach to business model development. Energy Policy 48:687-697

50. Terrado E, Cabraal RA, Mukherjee I (2008) Designing sustainable off-grid rural electrification projects: principles and practices. The World Bank, Washington DC

51. The World Bank (2008) REToolkit: a resource for renewable energy development. Washington DC

52. Tukker A (2004) Eight types of product-service: eight ways to sustainability? Experiences from suspronet. Wiley Inter Sci 260:246-260

53. Tukker A, Tischner U (2006) Product-services as a research field: past, present and future. Reflections from a decade of research. J Clean Prod 14(17):1552-1556

54. Tukker A, van den Berg C, Tischner U (2006a) Product-services: a specific value proposition. In: Tukker A, Tischner U (eds) New business for Old Europe. Product services, sustainability and competitiveness. Greenleaf publishers, Sheffield

55. Tukker A, Tischner U, Verkuijl M (2006b) Product-services and sustainability. In: Tukker A, Tischner U (eds) New business for Old Europe. Product services, sustainability and competitiveness. Greenleaf publishers, Sheffield

56. United Nations Environmental Programme (UNEP) (2002) Product-service systems and sustainability. Opportunities for sustainable solutions. UNEP, Division of Technology Industry and Economics, Production and Consumption Branch, Paris

57. Vezzoli C, Ceschin F, Diehl JC (2015) The goal of sustainable energy for all. SV J Cleaner Prod 97:134-136

58. Vanitkoopalangkul K (2014) Sustainable Design Orienting Scenario for Sustainable Product-Service System (S.PSS) applied to Distributed Renewable Energy (DRE) in low and middle income (all) contexts, Design Master thesis, School of Design, Politecnico di Milano

59. White AL, Stoughton M, Feng L (1999) Servicizing: the quiet transition to extended product responsibility. Tellus Institute, Boston

60. Wilson E, MacGregor J, MacQueen D, Vermeulen S, Vorley B, Zarsky L (2009) Briefing. Business models for sustainable development. International Institute for Environment and Development (IIED), London

61. Wilson E, Wood RG, Garside B (2012) Sustainable energy for all? Linking poor communities to modern energy services. International Institute of Environment and Development

62. Wise R, Baumgartner P (1999) Go downstream: the new imperative in manufacturing. Harvard Bus Rev 77(5):133-141

63. Yadoon A, Cruickshank H (2010) The value of cooperatives in rural electrification. Energy Policy 3:2941-2947

64. Zerriffi H (2011) Rural electrification. Strategies for distributed generation. Springer Science + Business Media 
Open Access This chapter is licensed under the terms of the Creative Commons Attribution 4.0 International License (http://creativecommons.org/licenses/by/4.0/), which permits use, sharing, adaptation, distribution and reproduction in any medium or format, as long as you give appropriate credit to the original author(s) and the source, provide a link to the Creative Commons license and indicate if changes were made.

The images or other third party material in this book are included in the chapter's Creative Commons license, unless indicated otherwise in a credit line to the material. If material is not included in the chapter's Creative Commons license and your intended use is not permitted by statutory regulation or exceeds the permitted use, you will need to obtain permission directly from the copyright holder.

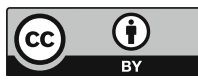

